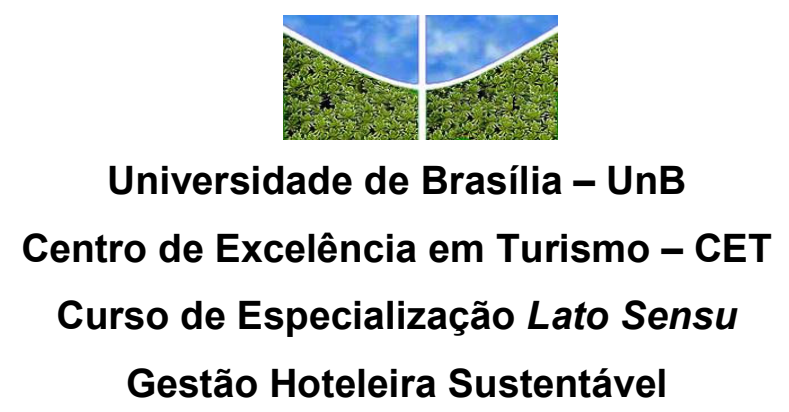

PAULO ROBERTO DA SILVA

GESTÃO DE PESSOAS E INVESTIMENTOS NO CONTROLE DO CONSUMO DE RECURSOS NATURAIS NÃO RENOVÁVEIS: Um Estudo de Caso no Hotel Meliá Brasil 21 em Brasília 
PAULO ROBERTO DA SILVA

\title{
GESTÃO DE PESSOAS E INVESTIMENTOS NO CONTROLE DO CONSUMO DE RECURSOS NATURAIS NÃO RENOVÁVEIS: Um Estudo de Caso no Hotel Meliá Brasil 21 em Brasília
}

\begin{abstract}
Projeto apresentado ao Curso de pósgraduação em Gestão Hoteleira Sustentável do Centro de Excelência em Turismo - CET da Universidade de Brasília - UnB, como requisito final à aprovação e obtenção do título de Especialista, sob a orientação do Professor MSc. Alexandre Maduro de Abreu.
\end{abstract}




\author{
Universidade de Brasília - UnB \\ Centro de Excelência em Turismo - CET \\ Pós-Graduação Lato Sensu
}

Curso de pós-graduação em Gestão Hoteleira Sustentável

\title{
GESTÃO DE PESSOAS E INVESTIMENTOS PESSOAS E INVESTIMENTOS NO CONTROLE DO CONSUMO DE RECURSOS NATURAIS NÃO RENOVÁVEIS: Um Estudo de Caso no Hotel Meliá Brasil 21 em Brasília.
}

\section{PAULO ROBERTO DA SILVA}

\author{
Aprovado por:
}

Orientador: Professor MSc. Alexandre Maduro de Abreu

Avaliador: Professora Dra. Iara Lúcia Gomes Brasileiro

Avaliador: Professor MSc. Luiz Carlos Spiller Pena

Brasília, de de 2008 
"Liberdade significa responsabilidade. Por isso tantos a temem."

Bernard Shaw 
Dedico

Este trabalho à minha família. 


\section{Agradeço}

A Deus,

À minha família, Ao meu Orientador, Professor Alexandre Maduro, Às demais pessoas envolvldas com este trabalho. 


\section{RESUMO}

Este estudo tem como objetivo pesquisar e dissertar acerca da aplicação de recursos financeiros e de gestão participativa no controle do consumo de recursos naturais não renováveis. Por esta razão a pesquisa pretende apresentar um projeto que fundamente a viabilidade econômica para a sua implementação no Hotel Meliá Brasil 21. A metodologia adotada para a pesquisa a classifica como dos tipos qualitativa e quantitativa, sendo que o público-alvo pesquisado consistiu em suporte para se aferir os níveis de conhecimento e de interesse de cada funcionário nesta questão ambiental de interesse mundial. Como resultados, pôde-se concluir que na investigação realizada sobre o tema, há viabilidade nos investimentos monetários e na formação das pessoas no tocante às propostas apresentadas para a sua implementação.

Palavras-Chave: Aplicação de Recursos, Consumo de Recursos Naturais, Hotel Meliá Brasil 21, Viabilidade, Investimentos. 


\section{SUMÁRIO}

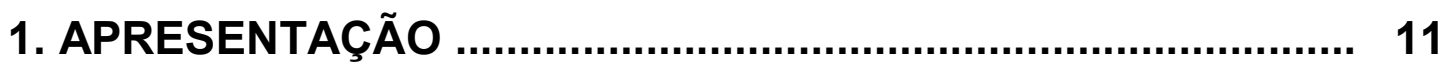

2. JUSTIFICATIVA ……........................................................ 12

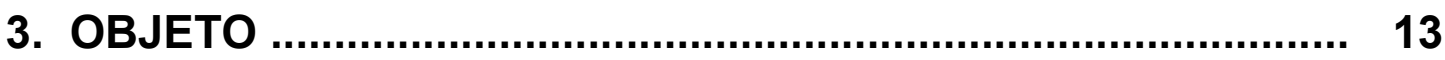

4. OBJETIVOS ………......................................................... 14

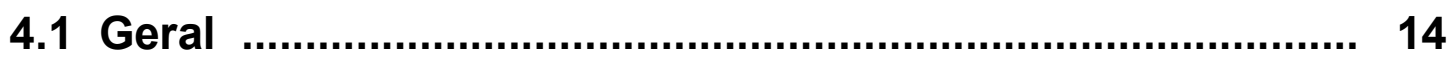

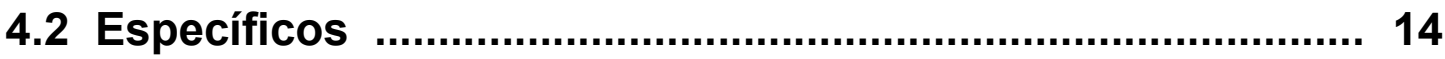

5. REFERENCIAL TEÓRICO .................................................... 15

5.1 Comportamento Organizacional .............................................. 15

5.2 Papéis desempenhados pelos gestores ……............................. 17

5.2.1 Papeis de relacionamento interpessoal ..................................... 17

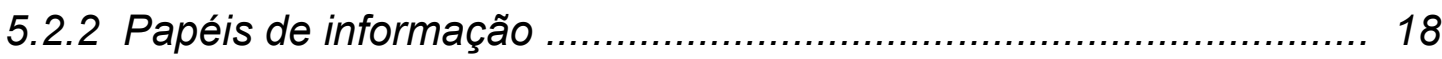

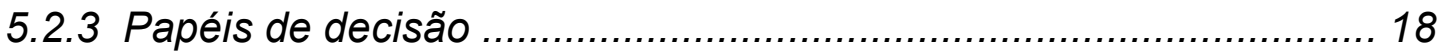

5.3 Habilidades requeridas dos gestores …......................................... 18

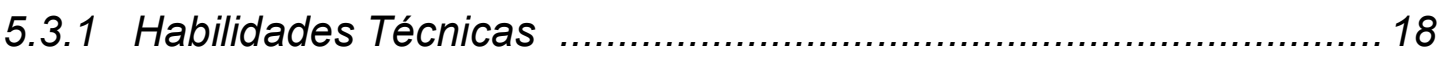

5.3.2 Habilidades Humanas ........................................................... 19

5.3.3 Habilidades Conceituais ........................................................ 19

5.3.4 Atividades eficazes versus atividades bem-sucedidas ................... 19

5.4 Evolução da Administração de Recursos Humanos ................... 20

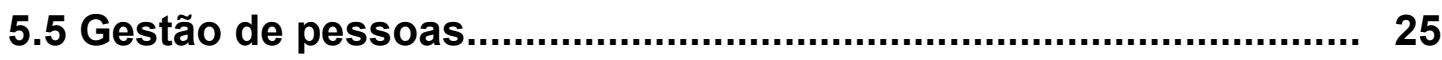

5.6 A organização e os problemas da mudança de gestão................ 28

5.7 Perfil dos líderes.......................................................................... 31

5.7.1 Perfeccionista............................................................................. 32

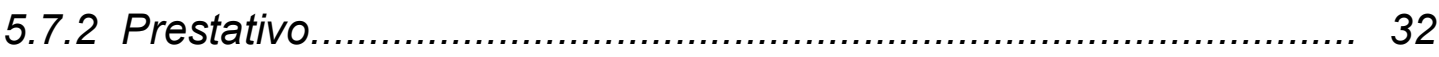

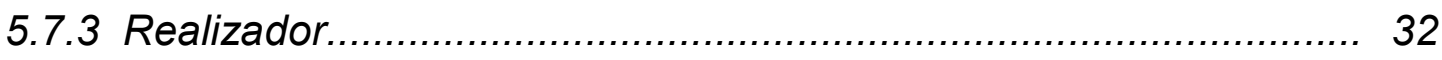

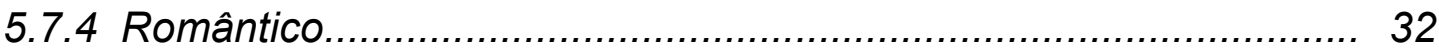

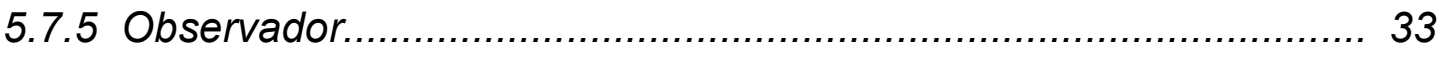

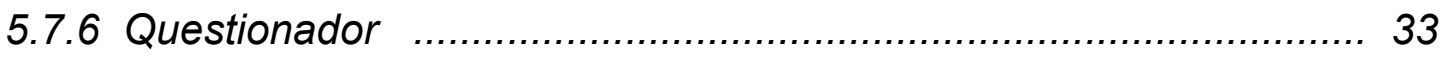

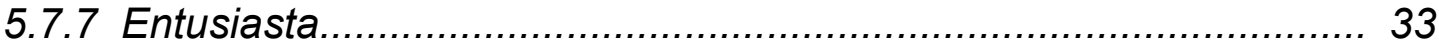

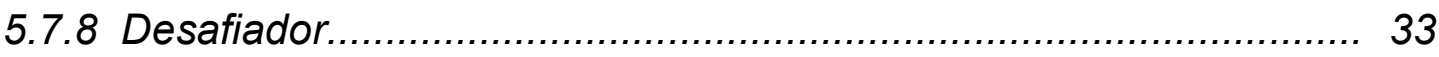




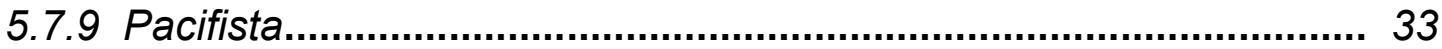

5.8 O Gestor diante de sua comunidade.............................................. 34

6. GESTÃO AMBIENTAL NOS HOTÉIS............................................. 37

6.1 Desenvolvimento Sustentável........................................................ 39

6.2 O sistema de gestão ambiental para o hotel................................... 40

7. METODOLOGIA DA PESQUISA.................................................... 43

7.1 Quanto à natureza ......................................................................... 43

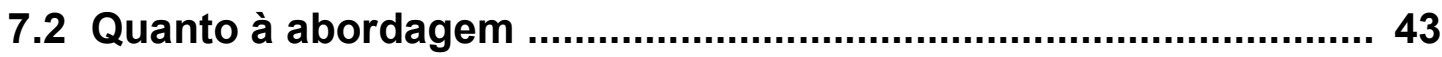

7.3 Quanto aos objetivos .......................................................................... .45

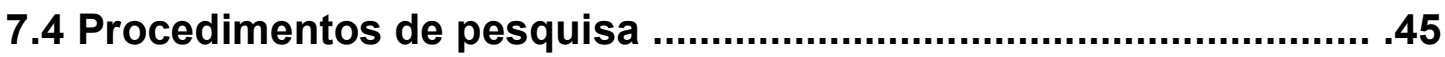

8. ESTUDO DE CASO - MELIÁ BRASIL 21 ........................................ 46

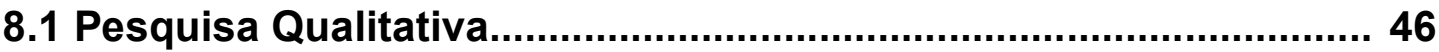

8.1.1 Questionário aplicado aos colaboradores do Hotel ......................... 46

8.2 Pesquisa Quantitativa ............................................................... 49

8.2.1 Análise dos dados estatísticos de consumo de utilidades ............... 52

9. CONSIDERAÇÕES FINAIS........................................................... 59

10. REFERÊNCIAS BIBLIOGRÁFICAS...................................... 61

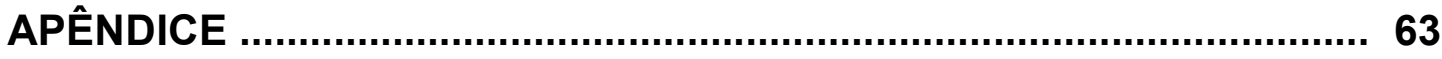

ANEXO 


\section{LISTA DE GRÁFICOS E TABELAS}

Tabela 1 - Atitudes de baixo consumo energético a serem adotadas.

Gráfico 1 - Atitudes de baixo consumo energético a serem adotadas 50

Tabela 2 - Atitudes de baixo consumo de água a serem adotadas 50

Gráfico 2 - Atitudes de baixo consumo de água a serem adotadas 50

Tabela 3 - Atitudes de coleta e/ou aplicação dos resíduos a serem adotadas ... 51 Gráfico 3 - Atitudes de coleta e/ou aplicação dos resíduos a serem adotadas... 51

Tabela 4 - Maneira que os funcionários seriam envolvidos. 51

Gráfico 4 - Maneira que os funcionários seriam envolvidos. 52

Tabela 5 - Comparativo do consumo anual de água entre Meliá-SP e MeliáDF. 53

Gráfico 5 - Comparativo do consumo anual de água entre Meliá-SP e MeliáDF. 53

Tabela 6 - Comparativo do consumo anual de energia entre Meliá-SP e MeliáDF. 53

Gráfico 6 - Comparativo do consumo anual de energia entre Meliá-SP e MeliáDF. 54

Tabela 7 - Planilha de Redução de uso de utilidades - Água. 55

Tabela 8 - Planilha de Redução de uso de utilidades - Energia Elétrica........... 57

Tabela 9 - Apresentação do Resultado Econômico do Projeto - Sintético........... 58

Tabela 10 - Informações acerca do estudo de viabilidade 58 


\section{APRESENTAÇÃO}

Ao longo dos anos as informações gerenciais acerca da evolução e controle dos gastos empresariais sempre ficaram restritos à alta cúpula gerencial das organizações. Isto se tornou um grande problema, pois as pessoas que efetivamente interferem na gestão dos custos encontram-se no centro e na base das estruturas organizacionais. Surge assim uma nova perspectiva de que as ações de menor impacto na natureza devem estar presentes nas atitudes diárias de cada funcionário.

Vale dizer que, na proporção em que as informações fluam democraticamente dentro das organizações, irão viabilizar a tomada de decisões dentro de um limite de competência previamente acordado.

Dessa maneira, com vista ao atingimento de tal finalidade, as pessoas se comprometem com os resultados, sentindo-se responsáveis pelas atitudes de menores gastos energéticos e os seus benefícios ao meio ambiente.

O resultado desta pesquisa busca dotar a organização de informações que viabilizem investimentos na sua matriz atual de gastos energéticos - água e eletricidade - e no convencimento e capacitação dos funcionários.

Nesse sentido, espera-se que, na medida em que os funcionários se envolvam pessoalmente na redução de consumo de água e energia, gerem benefícios financeiros para a organização e ambientais para a comunidade.

Contudo, imperativo se faz apresentar, oportunamente, a evolução histórica nas relações de trabalho que, ao longo dos anos, várias mudanças provocaram nas organizações. Por requerer, primordialmente, mudanças comportamentais e novas atitudes acerca da problemática sugerida, importante se faz enfatizar a relevância do papel dos executivos enquanto líderes dentro das organizações. 


\section{JUSTIFICATIVA}

A principal pretensão na eleição deste tema consiste fundamentalmente em comprovar a contribuição relevante que investimentos de recursos financeiros associados ao treinamento dos colaboradores para o seu convencimento - trarão, juntos, benefícios econômicos para a empresa e ecológicos para o meio ambiente e a sociedade. 


\section{OBJETO}

O objeto deste projeto consiste em comprovar à administração do Hotel Meliá Brasil 21, a importância do envolvimento dos colaboradores responsáveis diretamente pelo controle do consumo de recursos não renováveis, associado aos investimentos em estrutura física. Tal proposta far-se-á por meio de um "Estudo de Caso" acerca da matriz de consumo de utilidades ${ }^{1}$.

Nesse sentido, a pergunta-problema a ser respondida é:

- Considerando-se um mercado globalizado, competitivo e preocupado com o meio ambiente, quais os enfoques na gestão das pessoas e de investimentos em sistemas de menor consumo de recursos não renováveis que o Hotel Meliá Brasil 21 adotaria visando manter-se numa vanguarda tecnológica e de menor custo?

\footnotetext{
${ }^{1}$ Nomenclatura utilizada pela engenharia civil para identificar consumo de recursos naturais (água, energia, gás).
} 


\section{OBJETIVOS}

\subsection{Geral}

Pretende-se com este projeto, fundamentalmente, dotar a empresa de informações relevantes que a estimulem a efetuar os investimentos propostos em seu atual sistema de consumo de água e eletricidade e no envolvimento das pessoas que podem controlar melhor estes gastos.

\subsection{Específicos}

- Analisar o estágio atual de conhecimento dos colaboradores sobre questões do meio ambiente;

- Analisar o interesse dos colaboradores em assumir atitudes de menor consumo de recursos não renováveis;

- Apresentar os benefícios pessoais e organizacionais a serem atingidos ao se optar pelos investimentos propostos;

- Apresentar dados econômicos e financeiros que comprovem a viabilidade do projeto. 


\section{REFERENCIAL TEÓRICO}

\subsection{Comportamento Organizacional}

Embora na prática os executivos já tenham compreendido há muito tempo a importância das habilidades interpessoais para a eficácia da gestão, as escolas de administração, cujo modelo se iniciou nos Estados Unidos nos anos 50, demoraram um pouco para captar essa mensagem, uma vez que se prolongaram até o final da década de 80 , cujos currícolos enfatizavam os aspectos técnicos da gestão. Seu foco principal era em economia, contabilidade, finanças e métodos quantitativos.

Assim, temas como comportamento e habilidades interpessoais não recebiam quase nenhuma atenção. Nas últimas décadas, contudo, os professores começaram a perceber a importância do papel que o conhecimento sobre o comportamento humano tem na eficácia da gestão, e disciplinas voltadas para essa área foram sendo agregados ao currículo.

Nesse sentido, vale o que disse recentemente o diretor da escola de administração do MIT (Massachussets Institute of Technology):

Os estudantes de MBA podem se garantir com suas qualidades técnicas nos dois primeiros anos depois da conclusão do curso. Logo, entretanto, as habilidades de liderança e de comunicação se tornam decisivas para apontar quais as carreiras efetivamente vão decolar (ROBBINS, 2005, p. 2).

Para Robbins (2005), o reconhecimento da importância das habilidades interpessoais dos executivos está estreitamente relacionado com a necessidade das organizações de conseguir e reter funcionários com alto nível de desempenho. Independentemente das condições do mercado de trabalho, funcionários que se destacam estão sempre em falta. Empresas com a reputação de serem bons locais de trabalho - tais como Lincoln Electric, Adobe Systems, Southwest Airlines, Pfizer, SÃS Institute, Whole Food Markets e Starbucks - levam uma grande vantagem. Um estudo sobre a força de trabalho nos Estados Unidos revelou que salários e benefícios adicionais não são os motivos pelos quais uma pessoa gosta de seu emprego ou permanece nele. A qualidade do trabalho e o apoio recebido no ambiente de trabalho são muito mais importantes. 
Ter executivos com boas habilidades interpessoais é o mesmo que garantir um ambiente de trabalho mais agradável, o que, por sua vez, facilita a contratação e a manutenção de pessoas qualificadas. Além disso, criar um ambiente de trabalho agradável parece fazer sentido do ponto de vista económico. Por exemplo, as empresas apontadas como bons lugares para se trabalhar (com base na indicação das "100 melhores empresas para se trabalhar nos Estados Unidos") foram as que também apresentaram melhor desempenho financeiro (ROBBINS, 2005).

Assim, fica claro que as habilidades técnicas são necessárias, mas insuficientes para o sucesso das atividades de gestão. Hoje, com um ambiente de trabalho cada vez mais competitivo e exigente, os executivos não podem depender apenas de suas habilidades técnicas. Eles precisam também de habilidades interpessoais. E não são poucas as publicações que versam sobre as vantagens das habilidades difusas.

Uma vez que as organizações existem para atingir objetivos, alguém precisa definir estes objetivos e as possíveis formas de alcançá-los. O gestor é esse alguém. A função de planejamento engloba a definição das metas da organização, o estabelecimento de uma estratégia geral para o alcance dessas metas e o desenvolvimento de um conjunto abrangente de planos para integrar e coordenar as atividades (ROBBINS, 2005).

Outra função exercida pelo gestor é o controle. Para garantir que as coisas caminhem como devem, o executivo precisa monitorar o desempenho da organização. O desempenho real tem de ser comparado às metas previamente estabelecidas. Se há qualquer desvio significativo, é responsabilidade do executivo colocar a organização novamente nos trilhos. Esse monitoramento, a comparação e a possível correção são as tarefas da função de controle.

Na opinião de Robbins (2005) os executivos realizam trabalhos por meio do trabalho de outras pessoas. Eles tomam decisões, alocam recursos e dirigem as atividades de outros com o intuito de atingir determinados objetivos. Os executivos trabalham em uma organização, a qual pode ser definida como uma unidade social 
conscientemente coordenada, composta de duas ou mais pessoas, que funciona de maneira relativamente contínua para atingir um objetivo comum.

Com base nessa definição, indústrias e empresas de serviços são organizações, bem como escolas, hospitais, igrejas, unidades militares, lojas, delegacias de polícia e órgãos públicos, sejam eles municipais, estaduais ou federais. Assim, as pessoas que supervisionam as atividades das outras e que são responsáveis pelo alcance dos objetivos nestas organizações são os executivos (eles também são chamados de administradores, especialmente nas organizações sem fins lucrativos) (ROBBINS, 2005).

\subsection{Papéis Desempenhados pelos Gestores}

No final da década de 1960, um estudante de graduação do MIT, Mintzberg, realizou um cuidadoso estudo com cinco executivos para determinar o que eles faziam em seu trabalho.

\subsubsection{Papéis de Relacionamento Interpessoal}

Todo executivo precisa realizar tarefas de natureza cerimonial e simbólica. Quando o diretor de uma faculdade entrega os diplomas aos formandos na colação de grau ou quando um gerente de produção conduz um grupo de estudantes secundaristas em uma visita à fábrica, eles estão desempenhando o papel de figura de proa. Todos os executivos desempenham um papel de liderança. Este papel compreende a contratação, o treinamento, a motivação e a disciplina dos

funcionários. O terceiro papel desempenhado na área de relacionamento interpessoal é o de ligação.

Mintzberg (apud ROBBINS, 2005) descreve esta atividade como o contato com os fornecedores de informações para o executivo. Estes podem ser indivíduos ou grupos, dentro ou fora da organização. O gerente de vendas que obtém informações com o gerente de pessoal, dentro da mesma empresa, mantém com este uma relação de ligação interna. Quando o gerente de vendas tem contato com outros gerentes de venda, através de uma associação comercial de marketing, ele mantém com estes uma relação de ligação externa. 


\subsubsection{Papéis de Informação}

Todos os executivos obtêm, de algum modo, informações de outras organizações e instituições. Estas informações, sobre as mudanças nos gostos dos consumidores ou sobre os planos da concorrência, são obtidas geralmente por meio de leituras de revistas ou de conversas com outros profissionais. Mintzberg chama este papel de monitor. Os executivos também funcionam como um canal de transmissão destas informações para os demais membros da organização. Este papel é o do disseminador. Eles também podem desempenhar o papel de portavozes quando representam suas empresas em eventos externos.

\subsubsection{Papéis de Decisão}

Finalmente, Mintzberg (apud ROBBINS, 2005) identifica quatro papéis relacionados à função de fazer escolhas. No papel de empreendedores, os executivos iniciam e supervisionam novos projetos para a melhoria do desempenho de suas organizações. Como gerenciadores de turbulências, tomam atitudes corretivas diante de problemas imprevistos. Como alocadores de recursos, são responsáveis pela obtenção dos recursos físicos, humanos e financeiros. Por fim, os executivos desempenham o papel de negociadores quando discutem e barganham com as demais unidades da organização com o intuito de obter vantagens para a sua própria unidade.

Outra forma de considerar o que fazem os executivos é examinando as habilidades ou competências de que eles precisam para atingir seus objetivos com sucesso. Katz (apud ROBBINS, 2005) identifica três competências essenciais: técnicas, humanas e conceituais.

\subsection{Habilidades Requeridas aos Gestores}

\subsubsection{Habilidades Técnicas}

As habilidades técnicas englobam a capacidade de aplicação de conhecimentos ou especialidades específicas. Quando pensamos nas habilidades de profissionais como engenheiros civis ou cirurgiões-dentistas, geralmente temos 
em mente suas habilidades técnicas. Por meio da educação formal extensiva, eles obtiveram os conhecimentos $\mathrm{e}$ as práticas específicas de suas áreas. Evidentemente, os profissionais não detêm o monopólio das habilidades técnicas - e nem todas elas precisam ser aprendidas em escolas ou através de treinamentos formais. Todo trabalho requer algum tipo de habilidade especializada e muitas pessoas adquirem tal conhecimento no exercício de suas funções.

\subsubsection{Habilidades Humanas}

A capacidade de trabalhar com outras pessoas, compreendendo-as e motivando-as, tanto individualmente como em grupos, define as habilidades humanas. Muitas pessoas são tecnicamente proficientes, mas incompetentes nos relacionamentos interpessoais. Elas podem não ser boas ouvintes, incapazes de entender as necessidades dos outros ou ainda ter dificuldade para administrar conflitos. Como os executivos realizam coisas por meio do trabalho de outras pessoas, eles precisam ter habilidades humanas para se comunicar, motivar e delegar.

\subsubsection{Habilidades Conceituais}

Os executivos precisam ter capacidade mental para analisar e diagnosticar situações complexas. Esta tarefa requer habilidades conceituais. $O$ processo de tomada de decisão, por exemplo, exige que o executivo seja capaz de identificar problemas, desenvolver soluções alternativas para corrigi-los, avaliar essas alternativas e selecionar a melhor. Um executivo pode possuir competência técnica e humana, mas fracassar por causa da incapacidade de processar e interpretar racionalmente as informações.

\subsubsection{Atividades eficazes versus atividades bem-sucedidas}

Segundo Robbins (2005), numa pesquisa realizada por Luthans em 2001, foi possível avaliar os executivos com uma perspectiva um tanto diferente. Eles fizeram a seguinte pergunta: os executivos que sobem mais rapidamente na organização executam as mesmas atividades, e com a mesma ênfase, que aqueles 
que fazem o melhor trabalho? A tendência é acreditar que os executivos mais eficazes em suas funções são aqueles promovidos mais rapidamente. Mas, na prática, não é o que parece acontecer.

Segundo Robbins (2005), Luthans e seus colegas estudaram um grupo de mais de 450 executivos. Ficou constatado que estes estavam envolvidos em quatro atividades gerenciais:

1. Gerenciamento tradicional: Tomada de decisões, planejamento e controle.

2. Comunicação: Troca de informações rotineiras e atividades burocráticas.

3. Gestão de recursos humanos: Motivação, disciplina, administração de conflitos, recrutamento e seleção de pessoal e treinamento.

4. Interconexão (networking): Socialização, políticas e interação com o ambiente externo da organização.

Observa Robbins (2005), o executivo "médio" da pesquisa gastava 32\% de seu tempo com atividades do gerenciamento tradicional, 29\% em comunicação, $20 \%$ em atividades de gestão de recursos humanos e 19\% em atividades de interconexão. Contudo, a quantidade de tempo e esforço dispendidos nestas atividades variava bastante. Os executivos considerados bem-sucedidos (definido em termos da rapidez das promoções dentro da organização) demonstravam ênfase bem diferente daqueles considerados eficazes (definido em termos da avaliação do seu desempenho e da satisfação e comprometimento de seus subordinados).

Entre os executivos bem-sucedidos, as atividades de interconexão eram as de maior contribuição para o sucesso, enquanto a menor contribuição relativa foi a das atividades de gestão de recursos humanos. Entre os executivos eficazes, a comunicação proporcionava a maior contribuição e as atividades de interconexão, a menor. Um estudo mas recente realizado na Austrália (ROBBINS, 2005) confirma a importância da interconexão. Os executivos australianos que tinham grande atividade de interconexão recebiam mais promoções ligadas ao sucesso na carreira.

\subsection{Evolução da Administração de Recursos Humanos}

O movimento da Administração Científica, segundo Gil (2007, p. 18), tem origem com as experiências de Frederick W. Taylor, nos Estados Unidos, e Henri 
Fayol, na França. O objetivo fundamental desse movimento era proporcionar fundamentação científica às atividades administrativas, substituindo a improvisação e o empirismo.

Já Taylor (apud GIL, 2007, p. 18), com base em observações diretas, feitas em oficinas, concluiu que, de modo geral, os operários produziam muito menos do que poderiam produzir. A partir daí, desenvolveu seu sistema de Administração Científica. Assim, segundo aquele administrador, do ponto de vista técnico, esse sistema fundamentava-se na racionalização do trabalho, mais especificamente na simplificação dos movimentos requeridos para a execução de uma tarefa, objetivando a redução do tempo consumido.

Todavia, o taylorismo pretendeu ser algo mais. Ele envolvia uma verdadeira revolução mental por parte dos empregados e empregadores, que deveriam abandonar a luta pela repartição do produto do trabalho em favor da coordenação de esforços para aumentar esse lucro (GIL, 2007, p. 18).

Fayol, que foi durante boa parte de sua vida diretor de grandes minas e usinas siderúrgicas, também contribuiu para o movimento da administração científica, formulando a doutrina administrativa que passou a ser conhecida como fayolismo. Essa doutrina atribui aos subordinados uma capacidade técnica, que se exprime nos princípios clássicos e notórios da administração, isto é, $\mathrm{POC}^{3}$ : planejar, organizar, comandar, coordenar e controlar (GIL, 2007, p. 18).

Taylor contribuiu para fundamentar a Administração Científica ao afirmar que para diminuir os custos, a produção deveria ser em massa, em grande quantidade e aparelhada com tecnologia capaz de desenvolver ao máximo a produtividade dos operários. Afirmava também que o trabalho deveria ser altamente especializado, realizando cada operário uma única tarefa.

Além disso, propunha a remuneração pela produção e jornada menor de trabalho para aumentar a produtividade dos operários. Em razão de tantas mudanças, o movimento da Administração Científica difundiu-se amplamente e tornou-se uma das principais bases da organização industrial nas primeiras décadas do século XX (GIL, 2007, p. 19). 
O movimento de valorização das relações humanas no trabalho surgiu da constatação da necessidade de considerar a relevância dos fatores psicólogos e sociais na produtividade. As bases desses movimentos foram dadas pelos estudos desenvolvidos pelo psicólogo americano Elton Mayo (apud GIL, 2007, p. 19).

A importância das relações humanas passou a ser mais reconhecida no âmbito das organizações de maior porte e complexidade, nas quais as relações tendiam a ser cada vez mais impessoais e ficava claro que essa situação conduzia a conseqüências bastante desfavoráveis no campo da administração de pessoal.

A descoberta da relevância do fator humano na empresa veio proporcionar o refinamento da ideologia da harmonização entre capital e trabalho definida pelos teóricos da Administração Científica. Com efeito, pode-se dizer que as Relações Humanas constituem um processo de integração de indivíduos numa situação de trabalho, de modo a fazer com que os trabalhadores colaborem com a empresa e até encontrem satisfação de suas necessidades sociais e psicológicas.

Começa-se a falar em Administração de Recursos Humanos na década de 60, quando essa expressão passou a substituir as utilizadas no âmbito das organizações: Administração de Pessoal e Relações Industriais.

Atualmente, a maioria das empresas brasileiras de grande e médio porte mantém departamentos de recursos humanos, porém a adoção dessa designação parece estar relacionada ao interesse em apresentar uma característica de modernidade.

Na opinião de Gil (2007, p. 20), o aparecimento da Administração de Recursos Humanos deve-se à introdução de conceitos originários da Teoria Geral dos Sistemas à gestão de pessoal.

A Teoria Geral dos Sistemas tem origem nos estudos do biólogo alemão Ludwig von Bertalanffy (1901-1972). Ele verificou que certos princípios de algumas ciências poderiam ser aplicados a outras, desde que seus objetos pudessem ser entendidos como sistemas, fossem eles físicos, químicos, sociais, psicológicos etc. Isto fez com que ciências tidas como completamente estranhas entre si, em virtude de sua especialização, passassem a ser vistas sob uma óptica integradora. Por outro lado, alguns cientistas passaram a desenvolver uma Teoria Geral dos Sistemas que evidenciasse as semelhanças entre as ciências. Essa preocupação iniciouse no âmbito da Física e da Biologia, passando para as Ciências Sociais, notadamente para a Administração. 
Conforme Gil (2007, p. 21), o conceito de sistema já era amplamente utilizado nas ciências físicas e biológicas. Tanto é que em Astronomia há muito falase em sistemas planetários. Na Biologia, já é clássica a identificação dos sistemas ósseo, nervoso, circulatório e outros.

A partir da década de 50, o conceito passou a ser utilizado também nas Ciências Sociais. Assim, na Sociologia vários teóricos passaram a enfatizar o estudo dos sistemas sociais. Todavia, parece ser a Administração a ciência social para a qual mais contribuiu a Teoria Geral dos Sistemas, a ponto de tornar-se comum a classificação das atividades administrativas em sistemas: de produção, de comercialização, de recursos humanos e outros.

A Administração de Recursos Humanos pode, pois, ser entendida como a Administração de Pessoal baseada em uma abordagem sistêmica.

Segundo Gil (2007), o conceito de sistema, que é fundamental para essa abordagem, pode ser definido de diversas maneiras: como um conjunto de elementos unidos por alguma forma de interação ou interdependência; uma combinação de partes, formando um todo unitário; um conjunto de elementos materiais ou ideais, entre os quais se possa encontrar uma relação; uma disposição das partes ou elementos de um todo, coordenados entre si e que funcionam como estrutura organizada. Qualquer conjunto de partes unidas entre si pode, portanto, ser considerado um sistema, desde que as relações entre elas e o comportamento do todo sejam o foco da atenção.

Fica fácil, pois, definir uma empresa ou qualquer outra organização como um sistema, pois ela é constituída por elementos que de alguma forma interagem entre si e funcionam como uma estrutura organizada.

Como foi lembrado, o que caracteriza a Administração de Recursos Humanos é a adoção do enfoque sistêmico. Isto não significa, entretanto, que as empresas, ao manterem um departamento com o nome de recursos humanos, desenvolvem, de fato, a gestão sistêmica de seu pessoal. Muitas vezes, essa designação é dada unicamente para conferir ares de modernidade às empresas, ficando as atividades de pessoal restritas praticamente às rotinas trabalhistas e disciplinares. 
Quando uma organização adota o enfoque sistêmico na gestão de seus recursos humanos, passa a apresentar determinadas características, tais como:

a) interdependência das partes: quando se concebe uma administração como um sistema, torna-se possível identificar suas partes como subsistemas interdependentes. Com efeito, o sistema de administração de recursos humanos pode envolver, entre outros, os sub-sistemas de seleção e de treinamento. Estes, embora distintos, apresentam-se intimamente relacionados; o adequado funcionamento de um deles requer o feedback fornecido pelo outro;

b) ênfase no processo: a administração sistêmica é dinâmica. A organização não é vista como uma estrutura estática, mas como um processo em contínua mudança;

c) probabilismo: o discurso de uma organização sistêmica não é caracterizado pela certeza absoluta, mas pela probabilidade. O que, aliás, guarda coerência com o moderno enfoque adotado nas ciências humanas;

d) multidisciplinaridade: a organização sistêmica busca contribuições dos mais diversos campos do conhecimento: da Psicologia, da Sociologia, da Economia, da Medicina e outros. Quando uma equipe de recursos humanos é constituída por um grande número de pessoas, essas tendem a apresentar formação profissional bastante diferenciada;

e) concepção multicausal: Quando se adota o enfoque sistêmico, os fenômenos observados em relação aos indivíduos e aos grupos tendem a ser analisados com base na consideração dos múltiplos fatores que podem determinar ou interferir em sua ocorrência. Essa postura contrasta com as tradicionais, que pressupõem a causalidade com apoio em um fator único;

f) caráter descritivo: enquanto as organizações tradicionais estão mais preocupadas em definir o que deve ser feito, as organizações sistêmicas procuram antes compreender os fenômenos ligados à 
escolha dos objetivos e procedimentos afetos aos indivíduos que as compõem;

g) caráter multimotivacional: de acordo com as teorias psicológicas de caráter sistêmico, os atos humanos podem ser determinados por múltiplos motivos. As organizações, por sua vez, são constituídas para satisfação desses objetivos. Uma empresa pode ter como objetivo principal o lucro; entretanto, deve proporcionar também os meios para satisfação de outros objetivos. Um empregado pode, por exemplo, estar motivado para trabalhar não apenas em decorrência do salário, mas também da realização profissional ou da busca de status;

h) participação: o processo normal de tomada de decisões, de acordo com o modelo sistêmico, requer a participação daqueles que atuam nas unidades menores, nos subsistemas. Assim, numa organização sistêmica, as decisões sobre política de pessoal, por exemplo, só poderão ser tomadas depois de ouvidos integrantes dos subsistemas de recursos humanos: seleção, treinamento, cargos e salários e outros.

i) abertura: o adequado funcionamento de uma organização sistêmica requer permanente abertura em relação ao ambiente, bem como disposição para ajustar-se às alterações que aí se processam;

j) ênfase nos papéis: as organizações sistêmicas lidam com expectativas de papéis. Assim, seus membros precisam estar permanentemente informados acerca do que deles se espera em relação à organização, a seus colegas de trabalho e ao público externo (GIL, 2007).

\subsection{Gestão de pessoas}

O termo Gestão de Pessoas frequentemente substitui termos como Departamento de Pessoal, Departamento de Recursos Humanos, chegando a essa titulação mais recente e, acredita-se, poderá substituir Administração de Recursos Humanos, que é a mais comum entre todas as expressões utilizadas nos tempos atuais para designar os modos de lidar com as pessoas nas organizações. 
Essa nomenclatura tem mudado em prol de ressaltar que o termo Administração de Recursos Humanos é muito restritivo, pois dá a entender que pessoas trabalham numa organização apenas como recursos, ao lado dos recursos materiais e financeiros.

Por esse motivo, alguns autores, adeptos da Gestão de Pessoas, procuram designar as pessoas que trabalham nas organizações como cooperadores ou parceiros, não mais como empregados ou funcionários.

Conceituando Gestão de Pessoas, Gil (2007, p. 17), entende que “ [...] é a função gerencial que visa à cooperação das pessoas que atuam nas organizações para o alcance dos objetivos tanto organizacionais quanto individuais". Constitui, a rigor, uma evolução das áreas designadas no passado como Administração de Pessoal, Relações Industriais e Administração de Recursos Humanos.

Parece razoável admitir, com base na análise dos processos gerenciais desenvolvidos no passado - tais como Administração de Pessoal, Relações Industriais e Administração de Recursos Humanos - que a adoção deste ou de qualquer outro nome, por si só, não indica o que de fato as organizações fazem ou querem fazer.

No entanto, esse termo reflete uma concepção acerca das pessoas e das organizações que poderá ser compreendida de forma melhor mediante o estudo da evolução histórica do processo de gestão de pessoas.

As empresas, desde meados da década de 80 , vêm sofrendo sérios desafios, tanto de natureza ambiental quanto organizacional: globalização da economia, evolução das comunicações, desenvolvimento tecnológico, competitividade, etc. Nem todas conseguiram ajustar-se a esses desafios, e muitas das que sobreviveram passaram por experiências, como a reengenharia, a terceirização e o downsizing ${ }^{2}$, que produziram conseqüências de certa forma dramáticas para seu pessoal.

As críticas a esses procedimentos, aliadas a novas concepções acerca do papel dos indivíduos nas organizações, determinaram, sobretudo a partir da década

\footnotetext{
2 Termo inglês que representa a redução planejada do número de empregados e de níveis hierárquicos, para reduzir custos e aumentar a flexibilidade e adaptabilidade da organização.
} 
de 90, sérios questionamentos à forma como vinha sendo desenvolvida a Administração de Recursos Humanos nas organizações. Dentre as várias críticas, uma das que geraram maiores repercussões referia-se exatamente à terminologia utilizada para designá-la. Se tratadas como recursos, as pessoas precisam ser administradas, para obter-se delas o máximo rendimento possível. Conseqüentemente, tendem a ser consideradas parte do patrimônio da organização. Propõem, então, os críticos que as pessoas sejam tratadas como parceiros da organização. Como tais, passariam a ser reconhecidas como fornecedoras de conhecimentos, habilidades, capacidades e, sobretudo, o mais importante aporte para as organizações: a inteligência. Entendidas desse modo, as pessoas constituiriam o capital intelectual da organização, devendo, portanto, tratar seus empregados como parceiros do negócio e não mais como simples empregados contratados (CHIAVENATO, 1999d, p. 7).

Assim, verifica-se em algumas organizações a tendência para reconhecer o empregado como parceiro, já que todo processo produtivo realiza-se com a participação conjunta de diversos parceiros, como fornecedores, acionistas e clientes. Como cada parceiro dispõe-se a investir seus recursos numa organização, à medida que obtém retorno satisfatório, torna-se necessário valorizar o empregado, já que ele é o parceiro mais íntimo da organização. O peso do empregado, por sua vez, torna-se mais evidente numa organização à medida que sua força de trabalho esteja envolvida principalmente com atividades especializadas.

Esses fatos mostram que se está evoluindo para uma nova forma de gestão de recursos humanos, que vem sendo designada principalmente como Gestão de Pessoas, embora também se fale em Gestão de Talentos, Gestão de Parceiros, Gestão do Capital Humano, Gestão do Capital Intelectual etc. A Gestão de Pessoas, no entanto, constitui, ainda, uma tendência que se manifesta mais no meio acadêmico que propriamente nas empresas, visto que a expressão mais evidente de sua existência tem sido dada pelas revisões das obras relativas à gestão de recursos humanos e aos cursos que vêm sendo oferecidos por instituições especializadas.

De qualquer maneira, constata-se que a Gestão de Pessoas vem ganhando adeptos, já que muitas empresas anunciam a disposição para tratar seus 
empregados realmente como parceiros, incentivando sua participação nas decisões e utilizando ao máximo o talento das pessoas para a obtenção da sinergia necessária para seu desenvolvimento.

\subsection{A Organização e os Problemas da Mudança de Gestão}

Antes de levantar as possíveis condições de mudança existentes na organização, é preciso ter em mente que as organizações, de um modo geral, não se caracterizam pela mudança, mas, ao contrário, pela estabilidade. Isso se explica pelo fato de a organização social se definir pela existência de uma estrutura proposta com o fim de alcançar objetivos pré-determinados, de um modo considerado mais econômico. Se tais objetivos são vistos como permanentes ou fixos, o processo desenvolvido para sua realização também se apresenta estável. Essa estabilidade pode ser às vezes tão grande que chega a resistir a qualquer tentativa de mudança. Portanto, via de regra, as ações são reativas, pois os estímulos para a mudança provêm de fora (ALONSO, 1998).

Conforme Alonso (1998), não há dúvida de que a estrutura da organização tem muito a ver com a facilitação ou resistência ao processo de mudança; pode-se mesmo afirmar que qualquer esforço de mudança planejada é condicionado pelo estado do sistema em que ela ocorre.

A maior parte dos autores que estudaram o problema da mudança dentro das organizações concluíram que a hierarquia com as prerrogativas de status que ela confere aos funcionários administrativos é um dos maiores obstáculos para a introdução de inovação dentro da organização, uma vez que a tendência desse sistema é exatamente a manutenção do status quo.

Abbott, apud Alonso (1998) analisando as inovações técnicas apresentadas na organização e a sua relação com o processo de mudança, concluiu que tais inovações de técnicas, métodos, procedimentos de ensino em geral, nada têm a ver com a mudança da própria organização. O que acontece, segundo ele, é que os gestores, ao adotarem os novos procedimentos, apesar de demonstrarem entusiasmo e procurarem divulgá-los, não assimilaram os seus novos significados e 
passam a utilizá-los dentro de sua antiga concepção, portanto, dos estilos antigos, embora com novos nomes.

No fundo, a questão se prende a um processo de formação especializada do gestor acrescida de uma longa experiência, as quais não devem ser contestadas, mas, ao contrário, reforçadas através da preservação do status quo. Qualquer mudança significativa que envolva de fato alterações profundas no comportamento provoca insegurança e, portanto, é evitada ou mesmo rejeitada.

Conseqüentemente a mudança ou a inovação somente ocorrerá quando determinado programa da ação, anteriormente considerado satisfatório para atingir certos objetivos, se mostra incapaz de satisfazê-los. Claro está que isso implica em uma tomada de consciência deste fato, o que na prática não é tão simples porque geralmente o gestor procura evitar tal constatação, procurando continuar a ver o programa como satisfatório antes que inadequado. Uma vez que os critérios de mensuração e avaliação dos programas desenvolvidos não são tão objetivos como em outras situações, é razoavelmente fácil iludir-se quanto aos seus reais resultados.

Para Alonso (1998), propriedades da organização, tais como adequação da comunicação e distribuição da influência, têm poderoso efeito sobre a rapidez na adoção e durabilidade de uma inovação qualquer. Assim, por exemplo, a garantia de um eficiente progresso de comunicação entre os membros da organização, quer seja no sentido vertical quer no horizontal, é geralmente apontada como eficiente meio de facilitação do processo de mudança organizacional. Mesmo quando não oferece resistência aparente, a falta de compreensão dos fatores implicados ou o temor da ruptura da autoridade bem definida, levam freqüentemente a uma atitude senão inibidora, pelo menos pouco receptiva à inovação (ALONSO, 1998).

Há, portanto, uma inconsistência entre os dois tipos de papéis, gerandose o conflito que só será resolvido através de um sistema de interdependência entre os dois papéis, o que supõe solidariedade. É claro que os papéis hierárquicos que definem posições e, portanto, direitos e deveres, asseguram aos indivíduos uma condição de existência na organização, da qual não desejam abrir mão. Surge, pois, 
o comportamento de defesa do papel, num reforço da posição assumida sem possibilidade de questionamento.

Por outro lado, os especialistas também procuram assegurar seus direitos, constituindo grupos profissionais que lutam por determinada posição na estrutura administrativa. Começa, pois, a definir-se uma estrutura mais complexa, em virtude do aparecimento de novas funções cujo lugar exato na estrutura da organização não está definitivamente assegurado.

Embora a organização deva ser classificada entre as modernas organizações e, portanto, desfrutando de características comuns às demais organizações, tem, entretanto, características próprias que Ihe configuram uma especificidade de situação, que não pode ser ignorada ou desprezada no questionamento de sua estrutura e de seu dinamismo.

Para relacionar algumas de suas características específicas serão tomadas as idéias expostas por Miles e Huberman (1994) que são as seguintes:

a) ambigüidade de objetivos,

b) variabilidade de "inputs"

c) desempenho em termos de resultado pouco visível,

d) baixa Interdependência (relativa autonomia do gestor no seu trabalho),

e) vulnerabilidade (exposição a críticas externas),

f) controle final do trabalho feito por elementos do poder público ao invés de especialistas,

g) baixo investimento tecnológico das organizações.

Segundo Alonso (1998), diante de tais peculiaridades apresentadas pela organização, propõe-se que a inovação seja encarada por ela como condição necessária, mas que só se obterá mediante envolvimento total da organização nesse processo, exame da situação da organização quanto ao desempenho de sua função, e tomada de consciência por parte de seus membros da inadequação dos processos utilizados para alcançar objetivos mutáveis. 
Esse enfoque do problema deixa transparecer a idéia de que a organização só poderá atualizar-se em termos organizacionais, na medida em que os elementos nela envolvidos a compreenderem como sistema aberto, em constante intercambio com o seu ambiente. Este exige sempre novas coisas e, assim, leva à proposição de novos objetivos ou à adaptação dos antigos. Supõe ainda uma capacidade da própria organização avaliar-se e julgar a adequação dos recursos utilizados aos objetivos propostos para, em seguida, aceitar o desafio da mudança (ALONSO, 1998, p. 123)

Admitindo-se essa capacidade de adaptação constante da organização, o aparecimento dos "experts" não deveria ser visto como a condição única ou primeira da inovação, mas antes como um recurso instrumental de que a organização se serve para auxiliar tecnicamente na formulação de novos programas já tidos como necessários, embora requeiram auxílios especiais de implementação.

O problema que se põe para a administração organizacional consiste exatamente em estabelecer adequação entre os objetivos de manutenção e estabilidade da organização, e a necessidade de ajustamento constante as condições de cada momento histórico e social em que ela seja considerada.

Dessa forma, o comportamento administrativo neste tipo de organização deve ser alvo de considerações mais particulares em que seja preservada a essência da função, sua natureza específica, ao mesmo tempo que a sua especificidade quanto ao objetivo.

Nesse sentido, é importante mencionar que do futuro da organização e de sua gestão, obviamente, dependerá do tipo de lider que cuidará do seu comando. Dessa maneira, de acordo com Dimitrius e Mazzarella (2003), é possível relacionarse nove perfis de líderes, conforme adiante.

\subsection{Perfil dos líderes}

É fator determinante para todo gestor saber lidar com situações conflituosas, pois suas habilidades serão testadas freqüentemente e disso dependerá o avanço de sua carreira profissional. Um instrumento interessante que pode servir como ferramenta de avaliação é o Kilmann Conflit Mode Instrument (TKI - Thomas) que mensura as tendências comportamentais em uma situação de conflitos. 


\subsubsection{Perfeccionista}

Idealista, seguidor de princípios. Éticas e conscienciosas, essas pessoas têm um senso muito claro do que é certo ou errado. São professores e idealistas que sempre lutam para melhorar as coisas, mas com medo de errar. Organizadas, ordeiras e meticulosas, tentam viver conforme altos padrões, podem resvalar na crítica e no perfeccionismo.

\subsubsection{Prestativo}

Compreensivo, voltado para o lado interpessoal. Essas pessoas são amigáveis, generosas, empáticas, sinceras e afetuosas, mas podem ser também sentimentalistas e aduladoras, esforçando-se para agradar os outros a qualquer preço. Sua maior motivação é chegar perto dos demais e, por isso, muitas vezes tentam tornar-se necessárias.

\subsubsection{Realizador}

Adaptável, movido pelo sucesso. Essas pessoas são seguras de si, atraentes, ambiciosas, competentes, encantadoras e sempre prontas a agirem, elas podem deixar-se orientar muito pelo status e pela idéia de progredir na vida. Muitas vezes preocupam-se com a própria imagem e com o que os outros pensam a seu respeito.

\subsubsection{Romântico}

Romântico, introspectivo. Essas pessoas são atentas a si, sensíveis, calmas, reservadas. Emocionalmente honestas, não têm medo de revelar-se como são, mas estão sujeitas as flutuações de humor e inibições. Podem mostrar-se desdenhosas e agir como se não estivessem sujeitas às mesmas leis que os demais, ao mesmo tempo em que se esquivam das pessoas por sentirem-se vulneráveis e cheias de defeitos. 


\subsubsection{Observador}

Concentrado, cerebral. Essas pessoas são alertas, perspicazes e curiosas. Conseguem abstrair-se de tudo e concentrarem-se no cultivo de idéias e dons os mais complexos. Independentes e inovadoras, quando excessivamente dedicadas aos seus pensamentos e construtos imaginários, podem mostrar-se distantes e irritadiças.

\subsubsection{Questionador}

Dedicado, que valoriza a segurança. Essas pessoas são esforçadas, responsáveis e dignas de confiança, mas podem ser defensivas, evasivas e muito ansiosas, estressando-se só de reclamar do stress. Costumam ser indecisas e cautelosas, mas podem mostrar-se reativas, desafiadoras e rebeldes.

\subsubsection{Entusiasta}

Produtivo, sempre ocupado. Essas pessoas são versáteis, espontâneas e otimistas. Práticas, brincalhonas e joviais, podem mostrar-se também dispersivas e pouco disciplinadas, tendendo a assumir mais responsabilidades do que poderiam dar conta. Sua eterna busca de novas emoções pode levá-las a não terminar o que começaram, exaustas pelo excesso de atividade.

\subsubsection{Desafiador}

Forte e dominador. Essas pessoas são seguras de si, firmes e assertivas. Protetoras, talentosas e decididas, podem ser também orgulhosas e dominadoras. Por achar que precisam controlar o meio em que vivem, mostram-se contenciosas e intimidadoras.

\subsubsection{Pacifista}

Descomplicado, de fácil convivência. Essas pessoas são constantes, crédulas e receptivas. Têm bom gênio, bom coração e são fáceis de contentar, mas podem ir longe demais na disposição de ceder para manter a paz. Em sua ânsia de 
evitar conflitos, podem exagerar na complacência, minimizando todos os entraves que surgirem.

\subsection{O Gestor diante de sua comunidade}

No entendimento de Alonso (1998), a complexidade da vida moderna determina uma expansão no processo de especialização e, conseqüentemente, o surgimento de novas estruturas que se vão diferenciando para poderem desempenhar funções especificas anteriormente realizadas pela sociedade de modo mais genérico. Foi dessa forma que se procurou demonstrar o aparecimento das modernas organizações caracterizadas pela busca de uma ação racional ou ação eficiente, de modo a responder às demandas de ordem quantitativa e qualitativa das atuais sociedades. Estas considerações têm em vista os diversos tipos de atividades requeridas pela vida social moderna e, por isso, dizem respeito aos mais variados tipos de organizações existentes.

Um dos grandes problemas com que se defronta a organização atual é, sem dúvida, o da conciliação entre exigências de ordem quantitativa cada vez maiores, e o aumento de complexidade do processo organizacional que requer elaborações constantes, revisões nos processos de organização anteriormente desenvolvidos, bem como revisão nas atividades de integração e coordenação. Trata-se, portanto, de uma busca de eficiência da organização em relação às suas novas funções, o que só será possível na medida em que a organização reassuma a sua função geral na sociedade e redefina seus objetivos enquanto instituição especializada e legitimada socialmente.

Admite-se que só se obtém um enfoque dinâmico da estrutura da organização através da concepção de sistemas abertos anteriormente apresentada. Nesse enfoque foi proposto que toda e qualquer organização seja considerada como um sistema social, com unidade interna e identidade própria, embora interdependente de um sistema social maior. Com este sistema mantém relações constantes no duplo sentido de, por um lado, receber influências e retirar elementos para seu próprio funcionamento e, por outro lado, exercer influência, por meio da ação desenvolvida, sob forma de elaboração de algum "produto" ou "serviço". Em 
suma, foi demonstrada nessa concepção a natureza da organização do ponto de vista funcional, isto é, quanto ao preenchimento de uma função social.

Segundo Alonso (1998), a organização é tida como um conjunto de interrelações entre indivíduos. Nesse conjunto se definem setores especiais de comportamento para cada um deles, isto é, papéis sociais, interdependentes entre si e com relações de dependência também para com o meio social exterior. Dentro desta concepção a organização se apresenta como um sistema social com unidade e integridade ou entidade própria, ao mesmo tempo que é parte de um sistema social maior, a sociedade global.

Conforme Alonso (1998), a organização vista internamente, em sua estrutura, compõe-se de subsistências ou sistemas menores, cada um com sua especificidade própria, em si mesmos destituídos de sentido, mas resultantes do conjunto que os abriga. Esses subsistemas são ordenados entre si de modo a assegurar a consecução dos objetivos prefixados e definidos em termos sociais, mas interiorizados pela organização enquanto tal, na sua totalidade, e aceitos pelos respectivos executantes dos papéis.

Dado que um componente fundamental da estrutura de sistema social é a formação de um consenso moral geral que circunscreve direitos e obrigações, tornase decisivo que os participantes da organização estejam conscientes dos seus próprios deveres e direitos e, portanto, de seus próprios papéis bem como dos papéis dos outros participantes. Esta é, aliás, uma condição básica para a existência da ação cooperativa.

A distribuição de papéis muito embora seja condição necessária ao desenvolvimento de uma certa estrutura, que por sua vez é indispensável a ação cooperativa, esse processo não deve, entretanto, constituir-se em algo rígido e inflexível, mas permitir revisões e reajustamentos constantes à medida em que surgem novas situações, a organização se apresenta como um conjunto integrado de papéis sociais, definidos institucionalmente e, por isso, valorizados pela sociedade, os quais devem ser desempenhados de acordo com as expectativas correspondentes. Fica bem claro, entretanto, que esse conjunto assim definido somente deve ser preservado na medida em que satisfaz as condições funcionais da 
organização, isto é, na medida em que garante adequação aos objetivos estabelecidos socialmente.

Quando, pois, se modificam tais objetivos, essas condições estruturais devem ser revistas e os papéis redefinidos a partir das novas exigências, ou ainda ampliados enquanto tais, deixando margem inclusive à introdução de novos papéis, que anteriormente não se consideravam necessários. Conseqüentemente, é a compreensão correta dos objetivos que define a validade de uma estrutura existente e, portanto, legitima os papéis e as funções subjacentes a cada um deles, bem como sua interdependência. 


\section{GESTÃO AMBIENTAL NOS HOTÉIS}

A questão ambiental, que já vinha ganhando vulto nos últimos anos, tornou prioridade mundial após a divulgação dos relatórios do grupo da Organização das Nações Unidas - ONU sobre as mudanças climáticas e o aquecimento global.

Segundo Caon (2008), no setor hoteleiro, desde o início da presente década, algumas redes já haviam tornado a iniciativa de introduzir em suas políticas de gestão a adequação ambiental no âmbito dos seus hotéis, contudo, representando iniciativas esparsas.

Uma fase desse processo ocorre no Brasil a partir de dezembro de 2002, quando é assinado um convênio entre o Instituto Brasileiro de Turismo (EMBRATUR) e a Associação Brasileira da Indústria de Hotéis - ABIH, criando-se o novo sistema de classificação hoteleira, introduzindo, como critério classificatório, o conceito de responsabilidade e gestão ambiental.

A partir desse marco, aquilo que antes podia ser entendido como uma preocupação social de cada rede ou hotel individualmente passou a ser uma importante variável competitiva entre concorrentes no mesmo mercado: a gestão do hotel não só deve se preocupar com os impactos da sua operação no ambiente, mas também deverá buscar a sustentabilidade de suas atividades (CAON, 2008).

A explicação dessa mudança no setor hoteleiro deve ser buscada menos no aumento da "consciência ecológica" dos gestores e mais na própria lógica capitalista de "reprodução ampliada do capital".

A idéia de competitividade sempre foi o cerne do mercado concorrente e capitalista. A partir dessa lógica, a empresa, como, por exemplo, o hotel, deve buscar, de várias maneiras, se tornar mais atrativa quando comparada com as outras empresas com as quais concorre por determinado cliente. Uma dessas maneiras é a diferenciação, ou seja, oferecer algo diferente ou melhor do que suas concorrentes.

Assim, ser competitivo é ser melhor do que o seu melhor concorrente. Porém, ser "o melhor" em todo e qualquer aspecto elevaria sobremaneira os seus custos, o que, ao contrário do previsto, diminuiria sua competitividade no mercado 
em que atua, pois teria que praticar preços substancialmente maiores do que os de seus concorrentes, ou seja, não seria competitiva em preço (CAON, 2008).

É importante verificar se o preço é sempre relevante para o cliente. Entende-se que é importante a avaliação que é realizada pelo hóspede quanto à qualidade dos serviços prestados pelo hotel e os "critérios" para ele utilizados nessa avaliação. Ser competitivo será então "ser um pouco melhor do que meu melhor concorrente, mas só naquilo que meu cliente valoriza como importante" (CAON, 2008, p. 106).

Vale tomar como exemplo um potencial cliente pesquisando na internet as alternativas para a escolha de um hotel em determinada localidade. Encontra várias opções que, a priori, satisfazem suas necessidades; porém, um dos hotéis "préqualificados" informa que pratica a chamada gestão ambiental. Derivada da pressão exercida sobre a população em geral pelas diversas mídias nos últimos anos, a escolha de um hotel que não seja "ambientalmente correto" provocará no potencial cliente, no mínimo, um sentimento de culpa, pois essa escolha estará "prejudicando o planeta".

Entende-se que é nessa lógica econômica e psicossocial que se explicita a necessidade de os hotéis se adequarem às normas da gestão ambiental: se algum dos concorrentes a "fazem", os demais também serão forçados a fazer, sob o risco de perder a tão buscada competitividade.

Algumas entidades nacionais e internacionais, como a Associação Brasileira da Indústria de Hotéis - $\mathrm{ABIH}$ e a International Hotels Environment Initiative - IHEI, tem trabalhado na elaboração de programas de gestão ambiental especialmente dirigidos ao setor hoteleiro, cuja finalidade última seria aumentar a lucratividade diminuindo os custos operacionais, por meio da utilização de processos e tecnologias que possibilitem maior eficiência através da otimização do uso dos recursos escassos (principalmente água e energia elétrica), da diminuição do desperdício, da coleta seletiva do lixo e da utilização da biotecnologia para eliminação de componentes prejudiciais ao meio ambiente (CAON, 2008).

Nos estudos realizados por Caon (2008), o impacto da implantação desses programas pode ser bastante relevante no desempenho econômico do hotel: 
dados recentemente publicados indicam que os hotéis podem reduzir o consumo de energia em até $40 \%$ e em $50 \%$ o volume da água gasto por hóspede por diária.

\subsection{Desenvolvimento Sustentável}

Segundo Ruschmann (2006) o desenvolvimento turístico geralmente é enfocado do ponto de vista econômico, que utiliza uma abordagem baseada nos mecanismo dos preços, numa visão comercial. Porém, os aspectos sociais, culturais e ambientais da atividade não podem ser negligenciados e exigem envolvimento direto e estudo, por parte das entidades governamentais.

O turismo contemporâneo tem buscado ressaltar o aspecto natural, o que pode ser devido à busca do verde e à fuga dos tumultos dos grandes conglomerados urbanos, pelas pessoas que tentam recuperar o equilíbrio psicofísico, em contato com ambientes naturais, durante o seu tempo de lazer. De acordo com Faria (2001), a origem do conceito de sustentabilidade remete as relações entre os seres humanos e o meio ambiente (recursos naturais). Dessa maneira, fornece alguns conceitos:

a) Uso sustentável - ocorre quando os seres humanos utilizam os recursos renováveis, permitindo a reposição dos processos naturais e, consequentemente, a renovação indefinidamente, do sistema;

b) Crescimento sustentável - é uma questão fundamental se o crescimento econômico considera ou não a limitação de recursos, sem o que ocorrerá degradação do ambiente, pois não haverá crescimento sustentável sem o controle do crescimento populacional e do consumo per capta de recursos.

Nesse sentido, Matheus, Moraes e Caffagni (2005) entendem que

O conceito de desenvolvimento sustentável, embora polêmico, foi um grande avanço e representa uma tentativa de conseguir o bem-estar aliado à segurança de condições de vida satisfatórias no futuro (Bursztyn, 1994). Os caminhos que o homem percorre na busca por progresso, crescimento e desenvolvimento levam a impasses atuais relevantes, requerendo a escolha de estratégias adequadas que levem em consideração a preservação da qualidade ambiental. $O$ objetivo fundamental seria a promoção de um desenvolvimento sócio-econômico eqüitativo e com qualidade ambiental (MATHEUS, MORAES e CAFFAGNI, 2005, p. 2). 
O Programa das Nações Unidas para o Meio Ambiente (2004) aponta três princípios para o alcance das metas para o desenvolvimento sustentável, que são:

1. Equidade social: significa a disposição para reconhecer igualitariamente o direito de cada um;

2. Eficiência econômica: distribuição e a gestão dos recursos econômicos e financeiros feita de forma planejada, para garantir o funcionamento eficiente do sistema;

3. Prudência ecológica: adoção de ações que visam aos seguintes pontos:

a) Reduzir o consumo de recursos naturais e a produção de resíduos (lixo);

b) Intensificar as pesquisas e a introdução de tecnologias limpas;

c) Definir regras que permitam uma adequada proteção ambiental.

\subsection{O sistema de gestão ambiental para o hotel}

A principal finalidade de um Sistema de Gestão Ambiental (SGA) é alcançar, controlar e manter o nível de desempenho ambiental estabelecido pelas normas legais atualmente vigentes e relacionadas ao desenvolvimento sustentável.

As ações ambientais, sejam quais forem, serão sempre pautadas pelos chamados 3R: redução, reutilização e reciclagem.

As áreas de intervenção gerencial serão o monitoramento e a gestão da água, da energia - objetos desta pesquisa - além dos resíduos sólidos e produtos químicos. Essa intervenção se faz pelas seguintes atividades:

- Identificar as áreas de consumo que mais podem contribuir;

- Medir e comparar o consumo com unidades similares;

- Calcular a economia financeira e de recursos que o hotel pode ter aumentando sua eficiência ambiental; 
- Identificar tecnologias e dispositivos que possibilitem as reduções de consumo pretendidas;

- Detalhar as ações necessárias à implantação e orçar os investimentos necessários e redução de custos obteníveis;

- Implementar as ações para reduzir o consumo;

- Implantar sistemas de monitoramento para aferir os resultados obtidos; É fundamental que a implantação destes seja precedida pela identificação e definição de indicadores de desempenho;

- Implantar programas de educação ambiental e treinamento para os funcionários (BRASIL, 2008).

A maioria dos estudos desenvolvidos, lista medidas de fácil implantação e de resultados imediatos como primordiais para um programa de controle ambiental num hotel, quais sejam:

- Uso de dispositivos para redução do consumo de água e de energia elétrica;

- Sistema de compostagem de resíduos;

- Minimização da geração e coleta seletiva do lixo gerado (BRASIL, 2008).

Medidas de mais longo prazo também são citadas, como tratamento adequado de efluentes, através de estação de tratamento.

Comenta-se a seguir a utilização de tecnologias e dispositivos que permitem alcançar sensíveis resultados para algumas das medidas acima listadas.

Conforme Pertschi (2006),

estima-se que $40 \%$ do consumo de água de um hotel seja gerado nas unidades habitacionais, logo se deve tentar ao máximo a minimização do consumo de água. $O$ uso de redutores ou reguladores de vazão nas torneiras apresenta-se como uma das medidas mais eficazes e econômicas, pois vários fabricantes de loucas sanitárias, já o acoplam em seus produtos, permitindo uma redução de fluxo que representa uma economia de ate $30 \%$ na água utilizada (PERTSCHI, 2006). 
Ainda de acordo com o autor, as principais vantagens da adoção desta prática é a redução do consumo de água e energia em unidades habitacionais e área social e, ao mesmo tempo, a manutenção do conforto do hóspede, uma vez que o redutor não permite que o mesmo perceba a diferença, além da facilidade de instalação.

Outro equipamento também citado para ser utilizado no controle do consumo de água é a torneira automática, um dispositivo geralmente mecânico que controla o fluxo de água quando acionado, sendo instalado geralmente em áreas sociais e de funcionários (RICCI, 2002).

Segundo a TOI (2005), o processo de gestão do consumo de água num hotel deve estar estruturado nas seguintes atividades:

- Identificação das áreas de maior consumo;

- Monitoramento freqüente;

- Estímulo aos hóspedes para a reutilização de toalhas/roupas de cama;

- Orientação dos hóspedes e dos empregados para a necessidade de economia de água;

- Estímulo ao engajamento de departamentos, em especial a governança e a manutenção, em uma campanha ativa para a manutenção das instalações sanitárias, torneiras e chuveiros;

- Seleção de espécies de plantas nativas, resistentes a seca, para paisagismo e decoração. 


\section{METODOLOGIA DA PESQUISA}

A metodologia adotada, para cumprir o propósito deste projeto, foi segregada em três formas distintas de investigação: a) a primeira, por meio de um questionário aplicado aos colaboradores do Hotel Melia Brasil 21, em Brasília que buscou informações que possibilitassem inferir o nível de conhecimento e comportamentos diários no trabalho acerca de questões de impacto ambiental, água e energia primordialmente; b) a segunda se deu por uma investigação aprofundada dos dados sobre o consumo anual de água e eletricidade da empresa, e assim, poder compará-los com os dados de outro hotel, da mesma companhia, localizado na cidade de São Paulo, que possui condições físicas e estruturais similares, o que possibilitou uma comparação de realidades análogas; c) a terceira, por meio de revisão bibliográfica, na qual se pôde comparar e confirmar as informações e verdades científicas oferecidas pelos diversos autores pesquisados.

\subsection{Quanto a natureza}

Ambas as pesquisas são tidas como aplicadas, pois objetivam gerar conhecimentos para aplicação prática dirigida à solução de problemas específicos. Envolvem verdades e interesses locais.

\subsection{Quanto a abordagem}

A primeira fase é tida como qualitativa, pois no caso dos empregados do Hotel Meliá, a pesquisa valeu-se de questões abertas como forma de coleta de dados. Vale dizer que a investigação buscou questionar seus pesquisados para a produção de relatos com a qualidade de testemunho pessoal.

No questionário, entre os seus diversos tipos, o estudo desenvolveu uma abordagem que estimulou relatos mais livres do pesquisado. Considerou-se que há uma relação dinâmica entre o mundo real e o sujeito. É importante afirmar que a interpretação dos fenômenos e a atribuição de significados são básicas no processo de pesquisa qualitativa (OLIVEIRA, 1999). 
Os estudos de pesquisa qualitativa diferem entre si quanto ao método, à forma e aos objetivos. Conforme Godoy (1995a), a diversidade existente entre os trabalhos qualitativos apresenta características essenciais capazes de identificar uma pesquisa desse tipo, quais sejam: a) o ambiente natural como fonte direta de dados e o pesquisador como instrumento fundamental; b) o caráter descritivo; c) o significado que as pessoas dão às coisas e à sua vida como preocupação do investigador; d) enfoque indutivo.

Nesse sentido, a pesquisa em questão foi descrita como de caráter qualitativo, inclusive, e o seu objetivo é o de conhecer de modo conclusivo quanto ao nível de conhecimento dos empregados do Hotel Melia Brasil 21 no tocante ao controle dos gastos dos recursos não renováveis.

Em função da predefinição do público alvo a ser atingido, a forma mais adequada de se aferir dados relevantes sobre o nível de envolvimento e/ou conhecimento dos funcionários da organização acerca do problema, mostrou-se mais eficiente se aplicar um questionário pesquisando qualitativa e quantitativamente as informações.

- A primeira visa compreender as necessidades, motivações e comportamentos dos funcionários. Esta se distingue da segunda pela sua maior complexidade e profundidade nos métodos de análise (questões abertas é um exemplo).

- A segunda visa atingir por meio de um método que trabalha com indicadores numéricos e segue critérios estatísticos. Este tipo de pesquisa fornece informações sobre os hábitos de consumo, o grau de envolvimento de cada um com a problemática apresentada e o interesse em fazer novas escolhas.

Tanto o questionário quanto o levantamento aprofundado das informações de consumo anual de água e eletricidade são de abordagem quantitativa pois considera que tudo pode ser quantificável, o que significa traduzir em números as opiniões e informações para classificá-las e analisá-las. Requer o uso de recursos e de técnicas estatísticas (percentagem, média, moda, mediana). 


\subsection{Quanto aos objetivos}

Segundo (2002), a categorização da pesquisa classifica-se quanto aos fins e quanto aos meios. Quanto aos fins, essa pesquisa pode ser classificada como exploratória. Quanto aos meios, como sendo bibliográfica e estudo de caso.

A pesquisa é exploratória, pois visa proporcionar maior familiaridade com o problema, visando torná-lo explícito, constrói hipóteses, envolve levantamento bibliográfico, com pessoas que tiveram experiências práticas.

A metodologia a ser adotada na pesquisa terá como fundamentação um caráter descritivo, no qual os dados obtidos serão registrados, classificados, analisados, e, por fim, interpretados, de forma concisa e embasados em referências bibliográficas, com base em métodos comparativos, levantamento de dados e estudo de casos.

\subsection{Procedimento de Pesquisa}

A metodologia de estudo de caso que foi utilizada para a execução deste trabalho refere-se apenas aos dados que foram coletados, primeiro, diretamente com colegas na empresa por meio de entrevista, e em seguida, com dados estatísticos de consumo de água e energia, fornecidos pelo departamento de manutenção, de modo a aprofundar os estudos nesta unidade escolhida.

Assim, conforme Yin (2001, p. 33):

[...] o estudo de caso como estratégia de pesquisa compreende um método que abrange tudo - com a lógica de planejamento incorporando abordagens específicas à coleta de dados e à análise de dados. Nesse sentido, o estudo de caso não é nem uma tática para a coleta de dados nem uma estratégia de pesquisa abrangente [...]

Para a realização deste trabalho foram coletados dados por meio de três fontes principais: observação dos participantes, pesquisa bibliográfica e dados de estatísticos de consumo fornecidos pelo setor de manutenção. 


\section{ESTUDO DE CASO - MELIÁ BRASIL 21}

\subsection{Pesquisa Qualitativa}

\subsubsection{Questionário aplicado aos colaboradores do Hotel}

\section{Questão 1 - Grau de conhecimento sobre o aquecimento global}

De acordo com as respostas da questão 1, os entrevistados, no geral, sabem explicar o que é o aquecimento global, suas principais causas e quais as suas conseqüências para o planeta. Em linhas gerais, os entrevistados entendem que o aquecimento global é causado por inúmeros gases poluentes, como o carbono, lançados na atmosfera (por meio de indústrias, veículos com motores de combustão, usinas de geração de energia elétrica, altos índices de poluição nas grandes cidades, incêndios de florestas), que provocam um efeito estufa, gerando um aquecimento generalizado das temperaturas no planeta.

O aumento da temperatura gera mudanças climáticas bruscas e grandes conseqüências para o planeta, tais como: derretimento das calotas polares; aumento do nível dos oceanos e mares; mudança nos ciclos de chuvas e das estações do ano; extinção de espécies; maremotos; tsunamis e freqüentes aumentos e quedas bruscas de temperatura. Como medida paliativa, indica-se um projeto nas indústrias para diminuição desses gases.

Apenas um entrevistado considerou-se desinformando sobre o assunto, embora já tendo visto na televisão, admite que nunca leu ou se informou sobre o assunto.

\section{Questão 2 - Grau de comprometimento da qualidade da água num futuro próximo}

Conforme pôde ser analisado na questão 2, os entrevistados têm consciência da importância da preservação e cuidado com a qualidade da água que, enquanto recurso não renovável, pode se esgotar. 
Segundo eles, as reservas de água doce a nível mundial são escassas e encontram-se bastante comprometidas, pois, apesar de haver grande quantidade de água na Terra, a mesma não é ideal para o consumo humano. O Brasil é abençoado com o maior percentual dessas reservas naturais, no entanto, a poluição causada pelas indústrias, esgotos não tratados, aterros e lixões clandestinos, desperdícios domésticos e industriais, entre outros, fazem com que essa riqueza aos poucos seja seriamente ameaçada. As baixas nos níveis de água dos rios importantes no Brasil e no mundo têm causado o isolamento de várias comunidades e municípios que dependem das atividades de navegação.

Dentro das próximas décadas, a água será objeto de alto valor comercial. Se não houver um tratamento do esgoto e uma proteção das nascentes, no futuro não se terá água potável. Deve-se haver um planejamento público para que não ocorra o seu esgotamento.

\section{Questão 3 - Conhecimento acerca dos recursos energéticos (eletricidade) não renováveis}

De acordo com as respostas da questão 3, os entrevistados mostraram algum conhecimento sobre recursos energéticos não renováveis, entendendo que os recursos não renováveis se tornaram indispensáveis à vida moderna, à indústria, transporte, habitações, comércio, entretanto, essa exploração exagerada de recursos naturais sem medida de sustentabilidade está relacionada ao preocupante aquecimento global.

Dizem que no Brasil não há energia limpa, havendo, então, dois tipos de energia cuja geração é considerada suja: geração nuclear e de combustíveis fósseis. Os recursos energéticos de fósseis naturais (gás, petróleo) tendem a diminuir e acabar, pois apresentam uso limitado; e o uso de energia nuclear pode proporcionar muitas conseqüências catastróficas.

Concluem, então, que, como esses recursos são finitos, deve-se tentar economizar para essas fontes durarem mais e fazer estudo para se criar algo similar sem degradação. 


\section{Questão 4 - Interesse pessoal em adotar novas práticas de consumo}

Segundo análise da questão 4 , pode-se perceber que os entrevistados, no geral, alegam ter interesse no consumo sustentável, adotando algumas práticas no dia-a-dia, tais como: veículo bi-combustível de baixa cilindrada; reciclagem de materiais; iluminação à base de lâmpadas florescentes e não incandescentes; controle de consumo de água e energia. Essas práticas são motivadas pela necessidade de atuar localmente, pensando globalmente.

Ainda segundo eles, o Brasil tem indicativos de novas tecnologias de recursos energéticos naturais, tais como biodiesel e o álcool, que têm tido resultados bons em termos de novas práticas. Cabe à sociedade em geral aderir e incentivar tais tipos de práticas de consumo, o que contribui para a desaceleração dos efeitos do aquecimento global, entretanto, as iniciativas em se utilizar de novos recursos ainda são isoladas e, por isso, dispendiosas.

\section{Questão 5 - Motivação pessoal para envolver sua família, vizinhos e comunidade local}

Conforme a questão 5 , os entrevistados tentam envolver suas famílias, vizinhos e comunidade local em atitudes cotidianas como: reaproveitamento da água com que são lavadas as roupas para limpar calçadas e varandas; utilização de saco plástico de compras para armazenar lixo; reaproveitamento de gordura para confecção de sabão e outros.

De acordo com os entrevistados, essa é uma questão educacional, devendo ser envolvidos todos os segmentos da sociedade civil e governos. Entendem, ainda, que deve haver uma conscientização dos hábitos para preservação do planeta, além de ser uma responsabilidade como pai de família.

\section{Questão 6 - Grau do comprometimento da qualidade de vida das pessoas}

Em relação à questão 6 , há alguma divergência entre os entrevistados. Entendem que está ocorrendo um grande problema de saúde da população, que se encontra em estado de alerta geral - pessoas morrem por problemas respiratórios, 
infecções, enchentes, devido à poluição industrial do ar e rios; porém, a qualidade de vida somente será gravemente afetada, gerando sérios problemas futuros, se não houver interesse sobre essas questões.

\section{Questão 7 - A mudança de atitude das pessoas começa pelas nossas}

Em resposta à questão 7 , os entrevistados percebem que essa é uma questão educacional e reflexiva, que gera um processo de mudança. Acreditam que as pessoas se espelham nos exemplos dados. Concluem, então, que pequenas ações a nível local fazem grandes diferenças a nível global.

\subsection{Pesquisa Quantitativa}

Os questionários foram realizados nos departamentos operacionais da governança e da manutenção, pois são os que mais interferem nos sistemas de consumo de água e energia. Foram realizadas 19 entrevistas aleatórias num total de 54 funcionários. Entende-se ser uma amostra satisfatória, pelo elevado nível de interação funcional e de comunicação informal entre os pesquisados. E ainda as argumentações dos entrevistados possuem consideráveis similaridades.

1) Caso você fosse o gerente geral do hotel, que atitudes de baixo consumo energético você adotaria?

Tabela 1 - Atitudes de baixo consumo energético a serem adotadas

\begin{tabular}{|l|c|}
\hline \multicolumn{2}{|c|}{ Baixo Consumo Energético (\%) } \\
\hline Energias Alternativas & 22 \\
\hline Sensor de Presença & 22 \\
\hline Educação & 21 \\
\hline Lâmpadas Florescentes & 14 \\
\hline Grupos Geradores & 7 \\
\hline Outros & 14 \\
\hline Total & 100 \\
\hline
\end{tabular}


Gráfico 1 - Atitudes de baixo consumo energético a serem adotadas

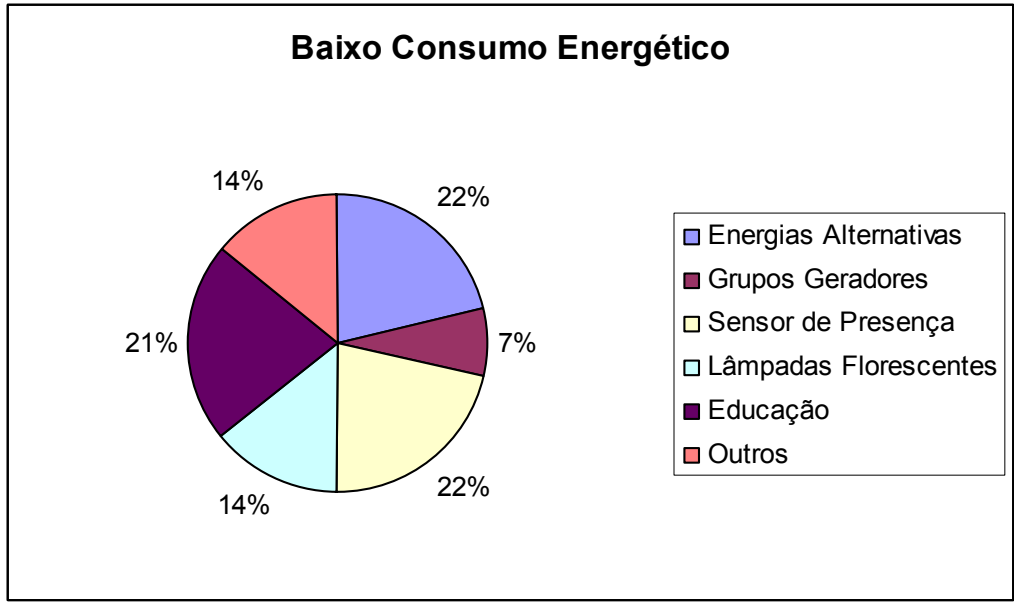

2) Caso você fosse o gerente geral do hotel, que atitudes de baixo consumo de água você adotaria?

Tabela 2 - Atitudes de baixo consumo de água a serem adotadas

\begin{tabular}{|l|c|}
\hline \multicolumn{2}{|c|}{ Baixo Consumo de Água (\%) } \\
\hline Redutores & 28 \\
\hline Reutilizar Água & 27 \\
\hline Educação & 27 \\
\hline Cisternas & 9 \\
\hline Outros & 9 \\
\hline Total & 100 \\
\hline
\end{tabular}

Gráfico 2 - Atitudes de baixo consumo de água a serem adotadas

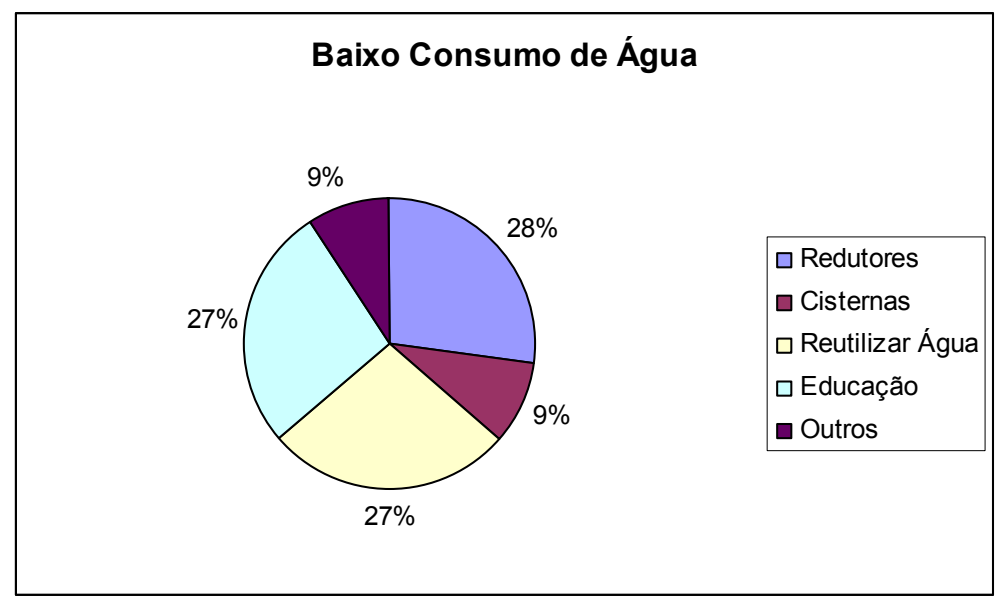


3) Caso você fosse o gerente geral do hotel, que atitudes de coleta e/ou aplicação dos resíduos você adotaria?

Tabela 3 - Atitudes de coleta e/ou aplicação dos resíduos a serem adotadas

\begin{tabular}{|c|c|}
\hline \multicolumn{2}{|c|}{ Aplicação de Resíduos (\%) } \\
\hline Coleta & 37 \\
\hline Reaproveitamento & 37 \\
\hline Biodegradáveis & 13 \\
\hline Conscientização & 13 \\
\hline Total & 100 \\
\hline
\end{tabular}

Gráfico 3 - Atitudes de coleta e/ou aplicação dos resíduos a serem adotadas

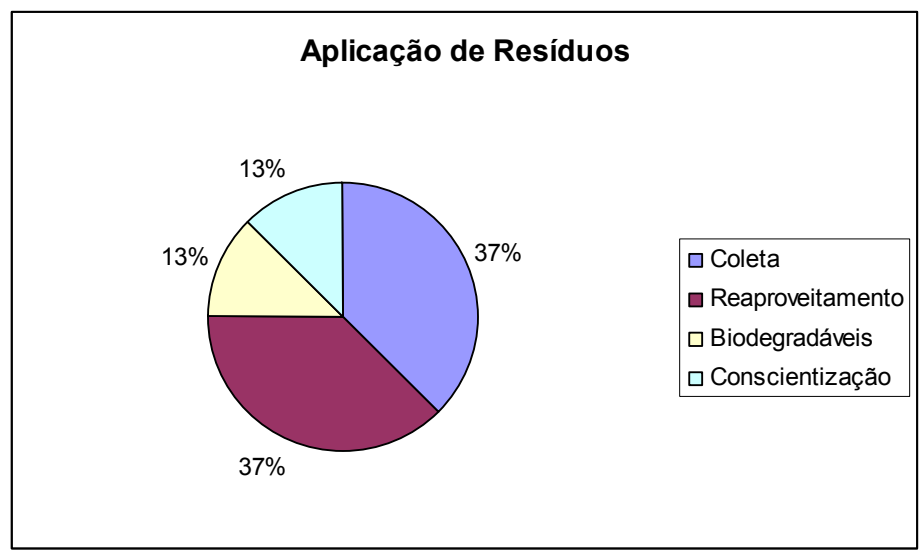

4) Caso você fosse o gerente geral do hotel, como você envolveria os funcionários neste objetivo?

Tabela 4 - Maneira que os funcionários seriam envolvidos

\begin{tabular}{|c|c|}
\hline \multicolumn{2}{|c|}{ Envolvimento de Funcionários (\%) } \\
\hline Conscientização & 66 \\
\hline Informação & 17 \\
\hline Premiações & 17 \\
\hline Total & 100 \\
\hline
\end{tabular}




\section{Gráfico 4 - Maneira que os funcionários seriam envolvidos}

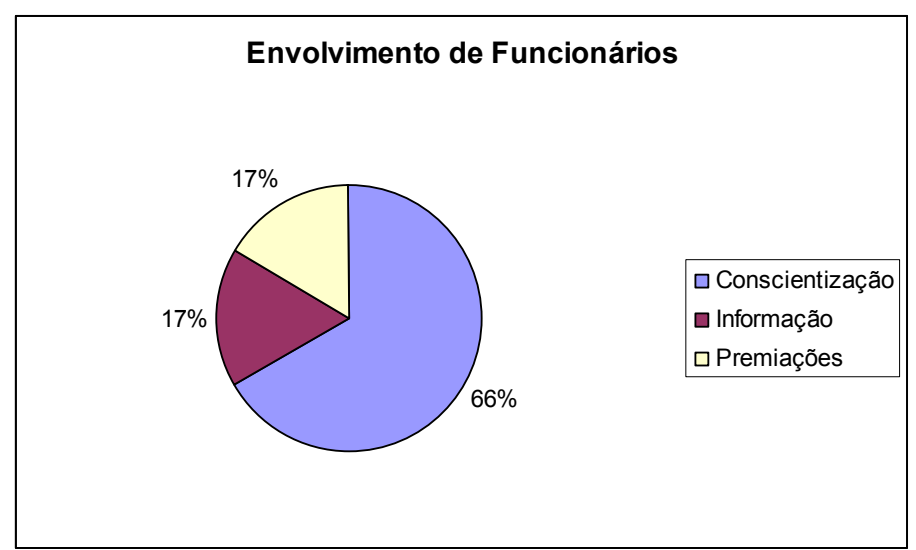

Ao analisar as tabelas e os gráficos de 1 a 4 acima, pôde-se constatar que as ações a serem implementadas pelos funcionários pesquisados, caso fossem imbuídos de poder de decisão - empowerment ${ }^{3}$, invariavelmente, incluiriam aspectos técnicos e comportamentais. Vale dizer que, com maior ou menor intensidade, todos associaram suas atitudes na gestão ao envolvimento dos funcionários. Assim se cumpre satisfatoriamente sua inclusão nos objetivos geral e específicos deste projeto. Neste sentido destaca-se nas Tabelas 1: Educação, 21\%; 2: Educação, 27\%; 3: Conscientização, 13\%; e 4: Conscientização, 66\%.

\subsubsection{Análise dos dados estatísticos de consumo de utilidades}

Com o intuito de estabelecer uma base entre o nível atual de consumo de água e eletricidade e o potencial de redução deste consumo, foram utilizados os dados estatísticos de gastos anuais de utilidades, fornecidos pelo departamento de manutenção do Hotel e se comparou com um laudo técnico que apresenta a "matriz de consumo" de outro hotel da mesma companhia com características físicas e estruturais similares, fornecido pelo Departamento de Engenharia do escritório corporativo em São Paulo.

\footnotetext{
3 Empowerment, expressão norte-americana para designar a delegação de autoridade, é uma abordagem a projetos de trabalho que se baseia na delegação de poderes de decisão, autonomia e participação dos funcionários na administração das empresas.
} 


\subsubsection{Consumo anual de água e energia: Meliá-SP x Meliá-DF}

Tabela 5 - Comparativo do consumo anual de água entre Meliá-SP e Meliá-DF

\begin{tabular}{|c|c|c|c|c|}
\hline \multicolumn{5}{|c|}{$\begin{array}{c}\text { Água } \\
\text { DF x SP }\end{array}$} \\
\hline & $\begin{array}{c}\text { Consumo } \\
\mathbf{H}_{\mathbf{2}} \mathbf{O}\left(\mathbf{m}^{\mathbf{3}} \mathbf{)}\right.\end{array}$ & $\begin{array}{c}\text { Qde. } \\
\text { mês } \\
\text { Hóspede }\end{array}$ & $\begin{array}{c}\text { Consumo } \mathbf{p} / \\
\text { Hóspede } \\
\left(\mathbf{m}^{\mathbf{3}}\right)\end{array}$ & $\begin{array}{c}\text { Gasto } \mathbf{p} / \\
\text { Ano }\end{array}$ \\
\hline ANO - DF & 37.171 & 69.185 & 0,5373 & $\mathrm{R} \$ 420.778$ \\
\hline ANO - SP & 33.634 & 65.792 & 0,5112 & $\mathrm{R} \$ 380.741$ \\
\hline Variação & $\mathbf{1 0 , 5 \%}$ & $\mathbf{5 , 2 \%}$ & $\mathbf{5 , 1 \%}$ & $\mathbf{R} \$ \mathbf{4 0 . 0 3 7}$ \\
\hline
\end{tabular}

Analisando os dados da Tabela 5 acima, fica evidenciado um consumo de 0,5373 $\mathrm{m}^{3}$ de água por hóspede ao ano no Hotel Meliá de Brasília, e 0,5112 $\mathrm{m}^{3}$ por hóspede ao ano no Meliá de São Paulo, representando uma variação percentual de $5,10 \%$ a mais no consumo de água, quando comparado ao consumo de São Paulo (v. Gráfico 5, abaixo).

Gráfico 5 - Comparativo do consumo anual de água entre Meliá-SP e Meliá-DF

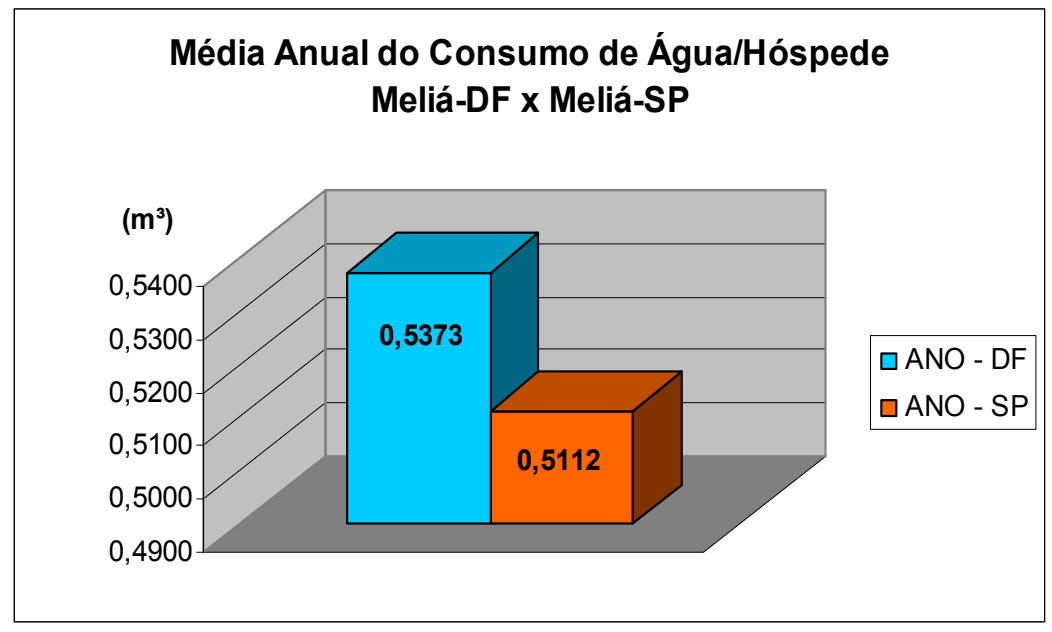

Tabela 6 - Comparativo do consumo anual de energia entre Meliá-SP e Meliá-DF

\begin{tabular}{|c|c|c|c|c|}
\hline \multicolumn{5}{|c|}{$\begin{array}{c}\text { Energia } \\
\text { DF x SP }\end{array}$} \\
\hline & $\begin{array}{c}\text { Consumo } \\
\text { Energia } \\
\text { (Kwh) }\end{array}$ & $\begin{array}{c}\text { Qde. } \\
\text { mês } \\
\text { Hóspede }\end{array}$ & $\begin{array}{c}\text { Consumo p/ } \\
\text { Hóspede } \\
\text { (Kwh) }\end{array}$ & $\begin{array}{c}\text { Consumo } \\
\text { anual em } \\
\text { Reais }\end{array}$ \\
\hline ANO - DF & 1.640 .782 & 69.185 & 23,7159 & $\mathrm{R} \$ 538.177$ \\
\hline ANO - SP & 1.508 .902 & 65.792 & 22,9346 & $\mathrm{R} \$ 494.920$ \\
\hline Variação & $\mathbf{8 , 7 \%}$ & $\mathbf{5 , 2 \%}$ & $\mathbf{3 , 4 \%}$ & $\mathbf{R} \$ \mathbf{4 3 . 2 5 7}$ \\
\hline
\end{tabular}


Analisando os dados da Tabela 6 acima, fica evidenciado um consumo de 23,7159 Kwh por hóspede ao ano no Hotel Meliá de Brasília, e 22,9346 Kwh por hóspede ao ano no Meliá de São Paulo, representando uma variação percentual de $3,4 \%$ a mais no consumo de água, quando comparado ao consumo de São Paulo (v. Gráfico 6, abaixo).

\section{Gráfico 6 - Comparativo do consumo anual de energia entre Meliá-SP e Meliá-DF}

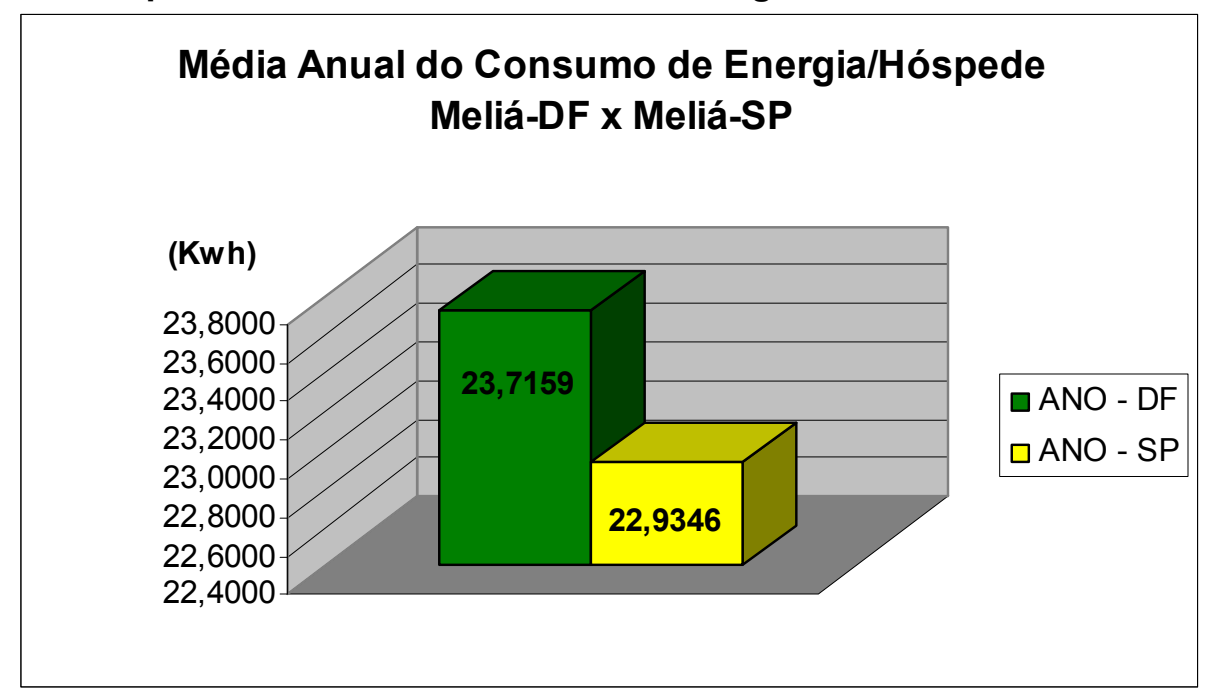

A tabela 7 abaixo apresenta as ações a serem adotadas, incluindo treinamento e capacitação dos funcionários e investimentos de recursos físicos e financeiros, dando um panorama de planejamento destas ações.

Segundo os dados fornecidos pelo departamento de engenharia (Tabela 7), os investimentos na capacitação e convencimento dos colaboradores que tenham suas tarefas associadas ao consumo destes gastos, podem proporcionar uma redução em até $0,49 \%$ no consumo de água e 0,30\% no consumo de energia, do total da eliminação dos desperdícios, contudo por questão de prudência, foi considerada uma redução na eficiência de $20 \%$, proporcionando um ganho de 0,39\%, conforme primeira ação apresentada na Tabela 8 , e de 0,24\%, conforme primeira ação apresentada na Tabela 8, respectivamente.

Atitudes de comunicar instantaneamente, ao departamento competente, sobre vazamentos de água detectados quando da faxina ou inspeção nos 
apartamentos; evitar ações compulsivas de dar descarga nos vasos sanitários para a higienização dos banheiros dos apartamentos sem comprovar sua necessidade; não revisar as lâmpadas deixadas ligadas pelo hóspede após sua saída; manter o black-out recolhido durante o dia evitando que o hóspede ligue as luzes para clarear o ambiente, são exemplos de ações que contribuem com a redução dos desperdícios destes insumos.

Após analisar os dados contidos nas Tabelas 5 e 6, acima, foi possível projetar os ganhos financeiros anuais, factíveis, com a implementação das ações propostas. A seguir estão relacionados os itens de ações sugeridas conforme o laudo. Os investimentos propostos são divididos em duas premissas, uma comportamental e outra em recursos físicos. Por questão de prudência adotou-se um percentual de eficiência de $80 \%$, apenas - o que equivale dizer que $80 \%$ de $7 \%$ corresponde a $5,6 \%$ de ganho de água - dos totais de benefícios possíveis de serem atingidos.

Tabela 7 - Planilha de Redução de uso de utilidades - Água ${ }^{4}$

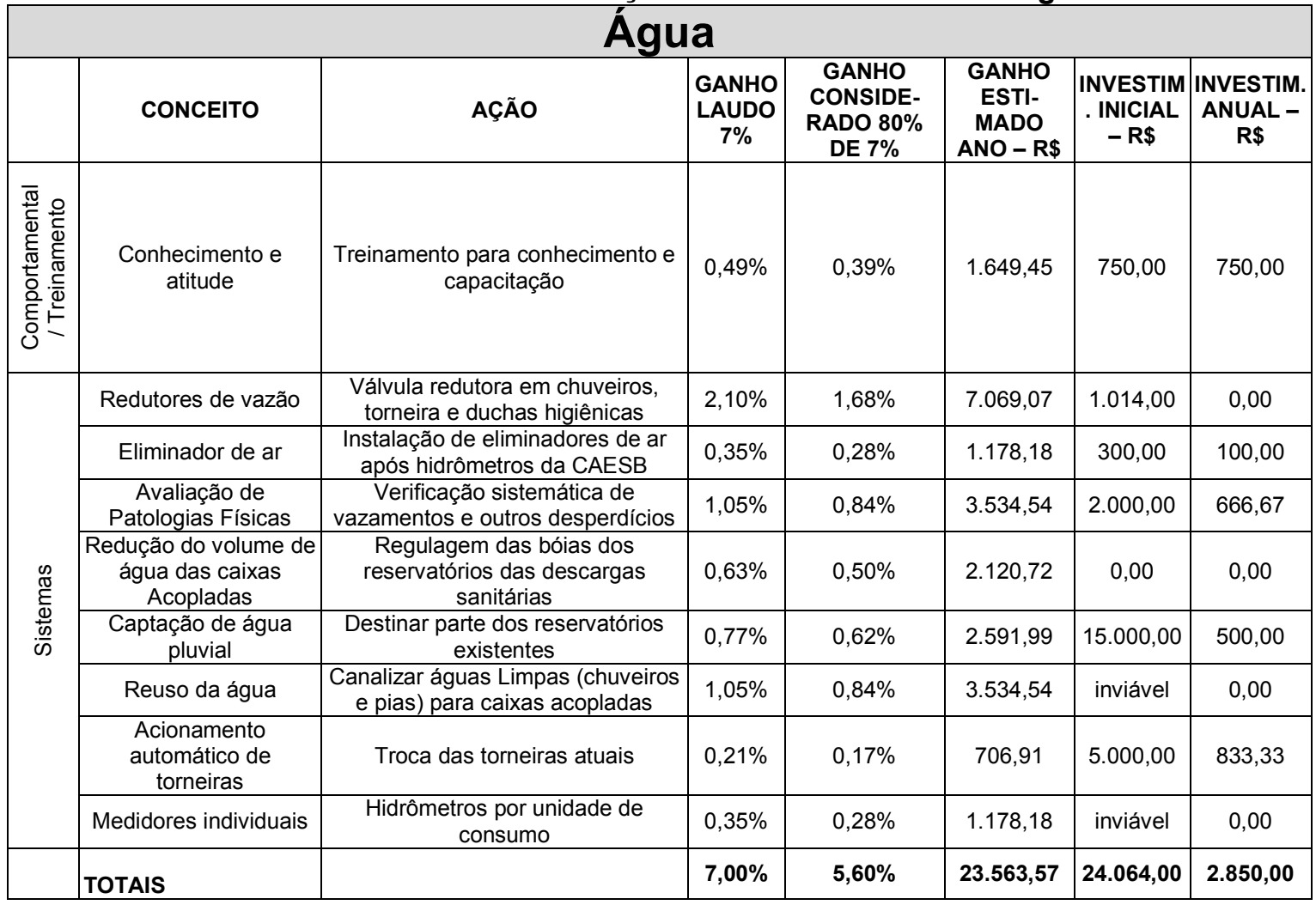

\footnotetext{
${ }^{4}$ Cf. Laudo Técnico anexo
} 
Seguindo a análise da tabela, elaborada a partir do laudo técnico, anexado neste projeto, os investimentos nas instalações de válvulas redutoras de vazão nos chuveiros, torneiras e duchas higiênicas, equipamentos que eliminem o ar presente na tubulação do sistema de distribuição de água da Caesb, rotinas sistemáticas para detecção de vazamentos, redução do volume de água nas caixas acopladas aos vasos sanitários, armazenamento de águas pluviais, substituição de torneiras atuais pelas torneiras de acionamento automático.

Conforme Tabela 7, acima, tais ações, juntamente às comportamentais, podem proporcionar uma redução de $7 \%$ no consumo de água, contudo, para tal foi considerado $5,60 \%$ no projeto como uma premissa conservadora.

Ainda, com base no laudo fornecido pela engenharia e reproduzida na Tabela 8, ações de substituição de lâmpadas, instalação de sensores para detecção de presença nos corredores e demais áreas de pouca circulação de pessoas, instalação de variador de freqüência no sistema de bombeamento hidráulico, controle sistemático de temperatura no sistema central de refrigeração do ar e manutenções preventivas em quadros elétricos, são ações que, juntamente às comportamentais, podem proporcionar uma redução de $5 \%$ no consumo de eletricidade, contudo, para foi considerado $4,00 \%$ no projeto como uma premissa conservadora. 
Tabela 8 - Planilha de Redução de uso de utilidades - Energia Elétrica ${ }^{5}$

\begin{tabular}{|c|c|c|c|c|c|c|c|}
\hline & CONCEITO & AÇÃO & $\begin{array}{l}\text { GANHO } \\
\text { LAUDO } \\
7 \%\end{array}$ & $\begin{array}{c}\text { GANHO } \\
\text { CONSIDERADO } \\
\mathbf{8 0} \% \text { DE } 7 \%\end{array}$ & $\begin{array}{l}\text { GANHO } \\
\text { ESTIMADO } \\
\text { ANO - R\$ }\end{array}$ & $\begin{array}{l}\text { INVESTIM. } \\
-\mathrm{R} \$\end{array}$ & $\begin{array}{l}\text { INVESTIM. } \\
\text { ANUAL - } \\
\text { R\$ }\end{array}$ \\
\hline $\begin{array}{l}\text { Comportamental } \\
\text { / Treinamento }\end{array}$ & $\begin{array}{l}\text { Conhecimento e } \\
\text { atitude }\end{array}$ & $\begin{array}{l}\text { Treinamento para } \\
\text { conhecimento e } \\
\text { capacitação }\end{array}$ & $0,30 \%$ & $0,24 \%$ & $1.291,62$ & 750,00 & 750,00 \\
\hline \multirow{8}{*}{ 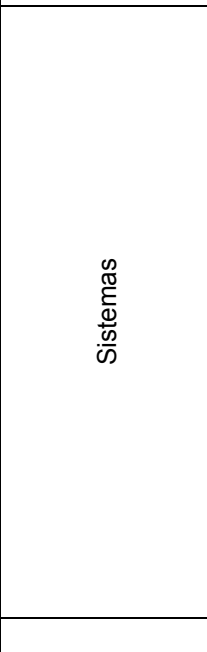 } & $\begin{array}{l}\text { Lâmpadas } \\
\text { Eficientes }\end{array}$ & $\begin{array}{c}\text { Substituição das lâmpadas } \\
\text { por lâmpadas "Frias" }\end{array}$ & $0,70 \%$ & $0,56 \%$ & $3.013,79$ & $27.040,00$ & $2.140,67$ \\
\hline & $\begin{array}{c}\text { Detectores de } \\
\text { presença e timmers }\end{array}$ & $\begin{array}{l}\text { Instalação de detectores } \\
\text { nos corredores e área de } \\
\text { pouca circulação }\end{array}$ & $0,70 \%$ & $0,56 \%$ & $3.013,79$ & $4.000,00$ & 400,00 \\
\hline & $\begin{array}{l}\text { Variador de } \\
\text { frequência }\end{array}$ & $\begin{array}{c}\text { Estação do equipamento no } \\
\text { sistema de bombeamento } \\
\text { Hidráulico }\end{array}$ & $0,80 \%$ & $0,64 \%$ & $3.444,33$ & $10.000,00$ & 200,00 \\
\hline & $\begin{array}{c}\text { Economizadores de } \\
\text { carga }\end{array}$ & $\begin{array}{l}\text { Energizar o apartamento } \\
\text { somente após entrada do } \\
\text { hóspede }\end{array}$ & $0,70 \%$ & $0,56 \%$ & $3.013,79$ & EXISTENTE & \\
\hline & Ajuste de set-points & $\begin{array}{l}\text { Controle sistemático de } \\
\text { temperatura no sistema de } \\
\text { ar condicionado central }\end{array}$ & $0,75 \%$ & $0,60 \%$ & $3.229,06$ & 0,00 & 0,00 \\
\hline & $\begin{array}{l}\text { Utilização de } \\
\text { motores de alto } \\
\text { rendimento }\end{array}$ & $\begin{array}{l}\text { Seleção/utilização de } \\
\text { motores elétricos mais } \\
\text { eficientes }\end{array}$ & $0,75 \%$ & $0,60 \%$ & $3.229,06$ & EXISTENTE & \\
\hline & $\begin{array}{l}\text { Manutenção } \\
\text { Preventiva }\end{array}$ & $\begin{array}{c}\text { Verificação sistemática de } \\
\text { barramentos e quadros } \\
\text { elétricos }\end{array}$ & $0,30 \%$ & $0,24 \%$ & $1.291,62$ & 600,00 & 600,00 \\
\hline & TOTAIS & & $5,00 \%$ & $4,00 \%$ & $21.527,06$ & $42.390,00$ & $4.090,67$ \\
\hline
\end{tabular}

Consoante o que se vê da Tabela 9, a seguir, o resultado financeiro obtido com os a implantação dos procedimentos sugeridos no preâmbulo deste capítulo, e utilizando as premissas orçamentárias discriminadas na Tabela 10, foi possível constatar uma economia da ordem de $\mathrm{R} \$ 150.039,00$ (cento e cinqüenta mil, e trinta e nove reais), num período de doze anos para o Hotel Meliá Brasília.

Vale dizer que não obstante à consideração da economia, é oportuno comentar o fato de que tais ações por si já representam fatores de apreciação e análise por parte da concorrência existente neste segmento de mercado altamente competitivo.

Importante se faz ressaltar aqui que várias das ações sugeridas por este projeto para a redução do consumo de utilidades, são coincidentes com os apontamentos descritos pelos funcionários quando investigados, fato que veio a ratificar a existência de um relativo senso comum das pesquisas e conseqüentemente uma maior contribuição aos propósitos deste projeto.

${ }^{5}$ Cf. Laudo Técnico anexo 
Tabela 9 - Apresentação do Resultado Econômico do Projeto - Sintético

\begin{tabular}{|l|r|}
\hline \multicolumn{1}{|c|}{ MELIÁ BRASIL 21 } & $\begin{array}{c}\text { TOTAL } \\
\mathbf{1 2} \text { ANOS }\end{array}$ \\
\hline REDUÇÃO DE GASTOS TOTAIS & 484.535 \\
\hline TOTAL REDUÇÃO AGUA & 226.210 \\
\hline TOTAL REDUÇÃO ENERGIA & 258.325 \\
\hline TOTAL GASTOS & 268.042 \\
\hline TOTAL GASTOS AGUA & 34.200 \\
\hline TOTAL GASTOS ENERGIA & 49.088 \\
\hline DEPRECIAÇÃO & 79.745 \\
\hline TAXA ATRATIVIDADE & 69.827 \\
\hline ENCARGOS SALDO NEGATIVO & 5.044 \\
\hline IMPOSTOS SOBRE O RESULTADO & 30.139 \\
\hline RESULTADO OPERACIONAL & 216.493 \\
\hline INVESTIMENTOS & 66.454 \\
\hline INVESTIMENTOS ÁGUA & 24.064 \\
\hline INVESTIMENTOS ENERGIA & 42.390 \\
\hline RESULTADO LIQUIDO PERÍODO & 150.039 \\
\hline
\end{tabular}

Tabela 10 - Informações acerca do estudo de viabilidade

\begin{tabular}{|c|c|}
\hline TAXA DEPRECIAÇÃO & $10,0 \%$ a.a \\
\hline TAXA ATRATIVIDADE & $0,5 \%$ a.m. \\
\hline PAYBACK & 3,6 anos \\
\hline TAXA INTERNA RETORNO & $27,71 \%$ a.a. \\
\hline
\end{tabular}

Considerando os dados apresentados e a constatação dos resultados econômicos a serem obtidos pelo Meliá Brasil 21 de Brasília, é possível afirmar e ao mesmo tempo propor que as medidas aqui apresentadas e fundamentadas redução que hoje já é uma realidade naquele hotel da rede em São Paulo - adote-se os mesmos procedimentos para o hotel objeto deste projeto. 


\section{CONSIDERAÇÕES FINAIS}

Este trabalho teve o objetivo de pesquisar e dissertar acerca da aplicação de recursos financeiros e de gestão participativa no controle do consumo de recursos naturais não renováveis. A pesquisa se desenvolveu na forma de Estudo de Caso no Hotel Meliá Brasil 21 no Distrito Federal.

A principal pretensão na eleição deste tema se pautou fundamentalmente na substancial contribuição que os empregados de uma organização passam a assumir na medida em que são focados sob novas perspectivas.

Ao longo dos anos as informações gerenciais sobre a evolução e controle dos gastos empresariais sempre ficaram restritas à alta cúpula gerencial das organizações, isto se tornou um grande problema, pois as pessoas que efetivamente interferem na gestão dos custos encontram-se no centro e na base das estruturas organizacionais. Surge assim uma nova perspectiva de que as ações de menor impacto na natureza devem estar presentes nas atitudes diárias de cada funcionário.

Vale dizer que, na proporção em que as informações fluam democraticamente, dentro das organizações, irão viabilizar a tomada de decisões dentro de um limite de competência previamente acordado. Dessa maneira, com vista ao atingimento de tal finalidade, as pessoas se comprometem com os resultados, sentindo-se responsáveis pela performance de menores gastos energéticos e seus benefícios ao meio ambiente.

O resultado desta pesquisa buscou dotar a organização de informações que viabilizem investimentos em sistemas em sua matriz atual de gastos energéticos - água e eletricidade - e na formação e capacitação dos funcionários.

Nesse sentido, espera-se que, na medida em que os funcionários se envolvam pessoalmente na redução de consumo de água e energia, gerem benefícios financeiros para a organização e ambientais para a comunidade.

No trabalho, foi possível apresentar a evolução histórica nas relações de trabalho que, ao longo dos anos, tantas mudanças provocaram nas organizações. Por requerer, primordialmente, mudanças comportamentais e novas atitudes acerca 
da problemática sugerida, na pesquisa enfatizou-se a relevância do papel dos executivos enquanto líderes dentro das organizações.

Considerando-se que o objeto deste projeto consistiu em comprovar e sugerir à Administração do Hotel Meliá Brasil 21 quanto à importância do envolvimento dos colaboradores responsáveis diretamente pelo controle de gastos, associado aos investimentos em estrutura. Tal proposta se fez por meio de um "Estudo de Caso" referente à matriz de consumo energético (água e eletricidade). Sobretudo, foi considerado o contemporâneo mercado globalizado e preocupado com o meio ambiente.

Por derradeiro, enfatiza-se que o acadêmico apresentou um projeto no qual fundamenta a viabilidade econômica para a sua implementação sendo que o público-alvo pesquisado consistiu em suporte para se aferir os níveis de conhecimento e de interesse de cada funcionário nesta questão ambiental de interesse mundial.

Como resultado da pesquisa empreendida, constatou-se que há viabilidade nos investimentos monetários e na formação das pessoas no tocante às propostas apresentadas para a sua implementação. 


\section{REFERÊNCIAS BIBLIOGRÁFICAS}

ALONSO, Myrtes. Transformações necessárias na escola e na formação dos educadores, Papirus, São Paulo, 1998.

BRASIL. FIESP. Melhore a competitividade com o Sistema de Gestão Ambiental SGA. Departamento de Meio Ambiente - DMA/FIESP, São Paulo, Disponível em: www.fiesp.com.br/ambiente/produtos_servicos/downloads/publicacao_iso.pdf, Acesso em 22 set. 2008.

CAON, Mauro. Gestão estratégica de serviços de hotelaria. São Paulo: Atlas, 2008.

CHIAVENATO. Idalberto. Gestão de pessoas. São Paulo: 1999.

DIMITRIUS, Jô-Ellan; MAZZARELLA, Mark. Decifrar Pessoas - Como entender e prever o comportamento humano. 30. ed. São Paulo, Alegro, 2003. 321p.

FARIA, Alexandre. Teorias de Estratégia, Estratégias de Pequenas Empresas e 'Estratégias Teóricas': Estudo de Caso em Rede Assimétrica no Setor de Telecomunicações no Brasil. IN: 25o Encontro Anual da ANPAD, Campinas.

GIL, Antônio Carlos. Gestão de Pessoas: Enfoque nos Papéis Profissionais - São Paulo : Atlas, 2007.

GODOY, Arilda S., Introdução à pesquisa qualitativa e suas possibilidades, in Revista de Administração de Empresas, v. 35, n. 2, Mar-Abr, 1995a , p. 57-63

MARCONI, Marina Andrade; LAKATOS, Eva Maria. Fundamentos da Metodologia Científica, 5. ed., São Paulo: Atlas, 2003

MATHEUS, Carlos Eduardo. MORAES, América Jacintha de, CAFFAGNI, Carla Wanessa A. Educação Ambiental para o Turismo Sustentável. São Carlos: Rima, 2005.

MILES, M.B.; HUBERMAN, A. M. Qualitative Data Analysis: an expanded sourcebook. $2^{\mathrm{a}}$ ed. London: Sage Publications, 1994.

MINTZBERG, H. LAMPEL, J. AHLSTRAND, B. Todas as Partes do Elefante. HSM Management. Jan/fev 1999, p. 100-108.

OLIVEIRA, Silvio Luiz de. Tratado de Metodologia Científica, 2. ed., São Paulo, Pioneira: 1999.

PERTSCHI, Ivan Karlo. Gestão Ambiental no Setor Turístico: um estudo com base na aplicação de indicadores ambientais em hotéis de grande porte em Foz do Iguaçu/PR. Dissertação: Universidade Federal do Paraná (2006) 
PNUMA (Programa das Nações Unidas para o Meio Ambiente). Perspectivas do meio ambiente mundial - GEO3. Tradução de Sofia Shellard e Neila B. Corrêa. Brasília: IBAMA, PNUMA e Universidade Livre da Mata Atlântica - UMA, 2004.

RICCI, R. Hotel - gestão competitiva no século XXI: ferramentas práticas de gerenciamento aplicadas a hotelaria. Rio de Janeiro: Qualitymark, 2002.

ROBBINS, Stephen Paul. Administração: mudanças e perspectivas. São Paulo: Saraiva, 2005.

RUSCHMANN, D. V. M. Turismo e Planejamento Sustentável: A Proteção do Meio Ambiente. 13. ed. São Paulo: Papirus Editora, 2006.

SILVA, Edna Lúcia da; MENEZES, Esfera Muszkat. Metodologia da Pesquisa e Elaboração de Dissertação. Laboratório de Ensino a Distância da UFSC, Santa Catarina, 2001.

TOI (Tour Operators Initiative for Sustainable Tourism Development). Um guia prático para boas práticas: gerenciando questões ambientais e sociais no setor de hospedagem. Tradução: Gert Werblowsky. São Paulo. Disponível em: $<$ http://www.toiinitiative.org/suply_chain/HotelGuidePortuguese.pdf $>$ Acesso em: 18 set. 2005.

VERGARA, Sylvia Constant. Projetos e Relatórios de Pesquisa em Administração. São Paulo: Atlas, 2002.

YIN R. K. Estudo de caso: planejamento e métodos. Tradução Daniel Grassi, 2ed., Porto Alegre: Atlas,2001. 


\section{APÊNDICE \\ BASE PARA QUESTIONÁRIOS}

Pesquisa qualitativa: (a ser investigado junto aos funcionários):

a. Grau de conhecimento sobre o aquecimento global;

b. Grau de comprometimento da qualidade da água num futuro próximo;

c. Conhecimento acerca dos recursos energéticos (eletricidade) não renováveis;

d. Interesse pessoal em adotar novas práticas de consumo;

e. Motivação pessoal para envolver sua família, vizinhos e comunidade local;

f. Grau do comprometimento da qualidade de vida das pessoas;

g. A mudança de atitude das pessoas começa pelas nossas.

\section{Pesquisa quantitativa (a ser investigado junto aos funcionários):}

a. Caso você fosse o gerente geral do hotel, que atitudes de baixo consumo energético você adotaria?

b. Caso você fosse o gerente geral do hotel, que atitudes de baixo consumo água você adotaria?

c. Caso você fosse o gerente geral do hotel, que atitudes de coleta e ou aplicação dos resíduos você adotaria?

d. Caso você fosse o gerente geral do hotel, como você envolveria os funcionários neste objetivo?

\section{Apontamento quantitativo:}

(a ser aferido nos controles internos da contabilidade e no setor de manutenção):

a. Índice atual de consumo ( $\mathrm{m}^{2}$ de água consumida por hóspede);

b. Índice atual de consumo (kwh de eletricidade por hóspede);

c. Comparação com índices padrões de consumo do Hotel Meliá Jardim Europa de São Paulo por se tratar de um empreendimento que possui características físicas similares. 


\section{ANEXO

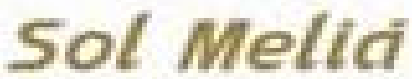 \\ HatiLE \\ REDUÇÃO DE USO DE UTILIDADES}

São Paulo, 12 de agosto de 2008.

Ao Engenheiro Tiago Eccard, chefe de manutenção do Melia Brasil 21.

Visando obter redução de uso de utilidades (água e energia elétrica) e melhorar a performance econômica do vosso hotel, informo que diante de estudos realizados em hotéis da Rede Sol Melia, considera-se que valores de 21,9789 $\mathrm{kWh} / \mathrm{hospede} / \mathrm{mês}$ de energia elétrica e $0,4890 \mathrm{~m} 3 /$ hóspede/mês de água são metas a serem atingidas nos próximos 2 anos pelos empreendimentos da rede. Vale lembrar que tais valores já foram atingidos em alguns de nossos hotéis.

Diante dos números médios apresentados por vossa senhoria de 23,7159 $\mathrm{kWh} /$ hóspede/mês de energia elétrica e $0,5373 \mathrm{~m} 3 /$ hóspede/mês de água durante os últimos 12 meses, solicitamos a adoção de medidas que visem à redução em até $7 \%$ do consumo de água e em até $5 \%$ do consumo de energia elétrica.

A partir de estudos de redução de consumo de utilidades, segue uma série de medidas adotadas em nossos hotéis, Melia, a exemplo do Melia Jardim Europa de São Paulo, e os seus respectivos impactos quantificados de maneira percentual no consumo de água e energia elétrica respectivamente.

Informo que, pela tipologia do empreendimento vistoriada em loco ao longo de 2007 e 2008, tratam-se de ações perfeitamente factíveis ao Melia Brasil 21.

Água

1- Comportamental e treinamento

O investimento em treinamento de pessoal pode reduzir em até $7 \%$ no consumo de água.

2- Sistemas

a. Redutores de vazão: estima-se uma redução em $30 \%$ no consumo de água utilizando-se redutores de vazão em chuveiros, torneiras e duchas higiênicas. 
b. Eliminadores de ar: estima-se uma redução em $5 \%$ no consumo de água utilizando-se eliminadores de ar nas linhas hidráulicas após os hidrômetros da concessionária de água.

c. Avaliação de patologias físicas: a verificação periódica de vazamentos e outros desperdícios podem trazer uma redução de até $15 \%$ do consumo.

d. Regulagem de descargas sanitárias: a regulagem do volume de água utilizada em descargas sanitárias pode reduzir em até $9 \%$ o consumo de água.

e. Captação de água pluvial: a captação de águas pluviais com o intuito de utilizá-las para outros fins como regar jardins e lavagem de pisos pode reduzir em até $15 \%$ o consumo.

f. Reuso da água: o aproveitamento da água já utilizada para o banho para outros fins, como por exemplo, a utilização da mesma para a descarga de sanitários, pode reduzir em até $15 \%$ o consumo.

g. Instalação de dispositivos automáticos: a instalação de torneiras automáticas pode reduzir em até $3 \%$ o consumo de água.

h. Medidores individuais: a medição e a conseqüente cobrança individualizada do consumo de água poderia trazer uma redução de $5 \%$ no consumo

\section{Energia elétrica}

1- Comportamental e treinamento

O investimento em treinamento de pessoal pode reduzir em até $7 \%$ no consumo de energia elétrica.

2- Sistemas

a. Lâmpadas eficientes: estima-se uma redução de $14 \%$ no consumo de energia elétrica utilizando-se lâmpadas frias.

b. Detectores de presença e timmers: estima-se uma redução em $14 \%$ no consumo de energia utilizando-se detectores de presença e timmers no circuito elétrico de iluminação e equipamentos.

c. Variador de freqüência: a utilização desse dispositivo fazendo o conjunto moto-bomba operar em uma rotação de melhor desempenho para o sistema hidráulico pode reduzir em até $14 \%$ o consumo de energia.

d. Economizadores de carga: a utilização desse dispositivo em uma unidade habitacional garante que o apartamento será energizado somente em caso de ocupação. Isso pode trazer uma redução em até $14 \%$.

e. Ajuste de set-points: Em um sistema de ar condicionado central, o controle otimizado de temperatura de água gelada pode gerar uma economia de até $14 \%$.

f. Utilização de motores alto rendimento: a seleção/utilização de motores mais eficientes podem economizar em até $15 \%$ o consumo. 
g. Eficácia na manutenção preventiva: manutenção em barramentos e quadros elétricos podem produzir uma economia de $6 \%$ no consumo de energia.

\begin{tabular}{c}
\hline Paulo Nogueira \\
CREA - 49129 / D \\
Gerente de Serviços Técnicos Brasil \\
Sol Meliá Hotels \& Resorts
\end{tabular}

